Dominguez R., Cannella S., Póvoa A.P., Framinan J.M. 2017. Information sharing in supply chains with heterogeneous retailers. Omega. DOI: https://doi.org/10.1016/j.omega.2017.08.005

\title{
Information sharing in supply chains with heterogeneous retailers
}

\author{
Roberto Dominguez ${ }^{a,}$, Salvatore Cannella ${ }^{b}$, Ana P. Barbosa-Póvoa ${ }^{a}, J^{\prime}$ se M. Framinan ${ }^{c}$ \\ ${ }^{a}$ Centre for Management Studies, Instituto Superior Técnico (CEG-IST), Technical University of Lisbon, \\ Portugal \\ bICAR, University of Catania, Catania, Italy \\ 'Industrial Management \& Business Administration Department, School of Engineering, University of \\ Seville, Spain \\ E-Mails: roberto.dominguez@tecnico.ulisboa.pt, cannella@unict.it, apovoa@tecnico.ulisboa.pt, \\ framinan@us.es \\ *Corresponding author: Roberto Dominguez, Centre for Management Studies (CEG-IST), Instituto \\ Superior Técnico, Technical University of Lisbon, Ave. Rovisco Pais 1, 1049-001, Lisbon, Portugal.
}

\begin{abstract}
This work analyses partial information sharing involving retailers with different operational configurations. Retailers are characterized by four operational factors, i.e., demand variance, lead time average, forecasting period and inventory policy. The findings show that the performance improvement based on information sharing depends on retailers' operational factors. Consequently, partial information sharing structures need to be carefully designed in order to achieve a substantial performance improvement. The results also serve to provide innovative recommendations to supply chain managers in order to efficiently implement information sharing mechanisms at retailers.
\end{abstract}

Keywords: Supply chain management; partial information sharing; heterogeneous retailers; bullwhip effect; multi-agent systems; dynamic performance. 

heterogeneous retailers. Omega. DOI: https://doi.org/10.1016/j.omega.2017.08.005

\section{INTRODUCTION}

\subsection{Context}

Globalization and a high volume of outsourcing has resulted in decentralized Supply Chains (SCs), shifting from a sequential linear SC to an increasingly complex global supply network (see e.g., Merzifonluoglu 2015, Annarelli and Nonino 2016, Li and Zhen 2016). SC partners have a higher autonomy, as they are part of many parallel chains at the same time (Zissis et al. 2015, Thomas et al. 2016). This fact reinforced the presence of conflicting objectives within the SC where competition exists for common resources and decisions are taken on individually based local incentives (Rached et al. 2016). The complexity of SCs has risen sharply in recent decades (Cardoso et al. 2015, Guertler and Spinler 2015), often leading to a lack of coordination among SC members. In this context, SCs from western economies to low-cost countries have been experiencing unpredictable and intensive deterioration of performance (Christopher and Holweg 2017). Additionally, the severe and synchronized trade collapse has amplified inefficiencies within the SCs, and subsequently led to detrimental phenomena such as the bullwhip effect (see e.g. Altomonte et al. 2012, Duan et al. 2015, Osadchiy et al. 2015). To overcome these inefficiencies, researchers and practitioners have been working on robust solutions. Among these, SC collaboration practices have been advocated as some of the most effective approaches (see e.g. Dejonckheere et al. 2004, Chen and Lee 2009, Trapero et al. 2012, Li and Zhang 2015, among others). At the core of collaboration practices lies information sharing (IS), a collaborative mechanism in which the supplier may obtain and utilize the demand and inventory status of the retailer (Huang et al. 2016).

During the last decade, the benefits of IS in decentralized SCs have been deeply researched with empirical studies of real cases (see e.g. Huo et al. 2014, Bian et al. 2016, Ren 2017), analytical methods (Chen and Lee 2009, Trapero et al. 2012, Ali et al. 2017), and simulation (Datta and Christopher 2011, Ramanathan 2014, Dominguez et al. 2015b, Cannella et al. 2017). In general, regardless of the adopted methodologies and the explored aspects of IS (e.g. reasons for sharing, what information to share with whom, how to share, as well as pre-requisites, drivers and barriers to IS, see Kembro et al. 2014), the majority of the literature agrees on the pivotal role benefits of IS practices in SC performance (Maghsoudi and Pazirandeh 2016). The expected revenues (e.g. a 
reduction in inventory holding cost, Hosoda et al. 2008) have been capturing the attention of SC practitioners (Kembro and Selviaridis 2015). As an example, a recent survey found that $61 \%$ of Chinese firms believe that IS is essential for business success (Bian et al. 2016). Basically, IS has been and continues to be a major topic in modern SC management and, contrary to popular belief, there is still significant need for more research regarding IS in SC (Kembro et al. 2014, Costantino et al. 2015).

\subsection{Problem Statement}

Despite the potential benefits of IS in SC, its practical implementation presents relevant difficulties (Fawcett et al. 2011, Spekman and Davis 2016). Full coordination among SC members, while desirable, is often impractical, since it is deemed to be too costly or too risky (Geunes et al. 2016). Making information available to other enterprises and managing the information requires investment in Information Technology (IT) and entails significant resource investments, which could result in a negative cost-benefit analysis (Chan and Chan 2010, Kembro et al. 2014). Additionally, companies need to bear the risk that information may be leaked intentionally or unintentionally by suppliers (Kong et al. 2013, Huang et al. 2016). Finally, resulting benefits of IS may be difficult to allocate in a reasonable way among SC partners (Shih et al. 2015).

Evidence of these barriers to achieve full collaboration among SC members can be found in practice. Accordingly, the Retailer-Direct Data Report of the Grocery Manufacturers Association (GMA) pointed out that retailers may not have an incentive to share data with suppliers (GMA 2009, Shang et al. 2016). Additionally, a study performed by Forrester Research on 89 retailers in 2006 reported that only $27 \%$ of retailers shared POS data (Shang et al. 2016). In this context, achieving a full IS (i.e., all SC members participate in IS, referred to as FIS in the following) is not always possible. Thus, in practice, partial IS is found to be prevalent (Shnaiderman and Ouardighi 2014, Xu et al. 2015). However, in the scientific literature, partial IS has been rarely analysed because the majority of studies dealing with IS assume a full collaboration practice among all members (Holmström et al. 2016). In light of these considerations, studying the dynamics of SC in scenarios where FIS cannot be achieved represents a challenge for researchers and may bring potential benefits for industry. 
To the best of the authors' knowledge, up to now, partial IS has been addressed in literature in five relevant studies. Ganesh et al. (2014a,b) and Costantino et al. (2014) analyse the impact of different degrees of collaboration on SC performance (i.e., inventory holding and shortage costs, bullwhip effect and/or customer service level) in a serial SC, while Lau et al. (2004) analyse partial IS in more complex SCs, in particular in three divergent SCs. Finally, Huang and Iravani (2005) focus on one capacitated manufacturer and two retailers under a $(\mathrm{Q}, \mathrm{R})$ inventory policy, where the former receives demand and inventory information from only one of the retailers.

The above-mentioned works have significantly contributed to the unexplored topic of partial IS by showing two novel insights:

(1) Retailers should be the first members to be involved in IS (Ganesh et al. 2014a,b, Costantino et al. 2014, Lau et al. 2004), since they report the highest performance improvement to the SC.

(2) The operational factors (OFs) of retailers, such as market shares and order sizes, may have a significant impact on the benefits provided by the IS practice under partial collaboration (Huang and Iravani 2005).

The former insight reasserts the central role of retailers for the efficacy of IS, while the latter suggests that SCs characterized by heterogeneous retailers (i.e., retailers with different OFs such as lead times, order policies, market demand, etc.), may perform differently under the same IS practice. Both insights open interesting challenges for researchers and advocate important implications for industry, as they point out the relevance of exploring the efficiency of partial IS at retailers when these are heterogeneous. According to these insights, we formulate the following research questions: how retailers with different OFs may impact on SC performance when they share information about customer demand? Which retailers' OFs are more relevant in order to consider a retailer as a potential partner for the IS scheme and at what extent?

\subsection{Objective}

Motivated by the above considerations, in this paper we aim to contribute to the existing literature by assessing how heterogeneous retailers, characterized by different critical OFs (i.e., demand variability, average lead time, forecasting period and inventory 
policy), may improve SC performance by sharing (or not) true demand information. We assume that due to the decentralized nature of modern SCs, companies and, specifically, the retailers, are autonomous members who work for their own goals and interests and thus, retailers' OFs are considered as exogenous factors. In this manner we aim to provide recommendations to SC managers on how to properly exploit the benefits of implementing IS practices with retailers by identifying which retailers provide a higher contribution to SC performance.

To fulfil the research objective, we focus on a four echelon SC (i.e., Factory, Distributor, Wholesaler and Retailer) in which each echelon is characterized by one member with the exception of the Retailer's echelon, which is constituted by four members. We compare different partial IS scenarios (some retailers may share demand information, while some others may not share information) under two different hypothesis: (1) homogeneous retailers and (2) heterogeneous retailers. Under the former hypothesis we analyse the SC performance when identical retailers are involved in IS one by one, on variety of SC configurations. Under the latter hypothesis we assess the impact on SC performance of involving retailers with different OFs in IS. SC performance is measured using a set of system level metrics (i.e., Bullwhip Slope, Inventory Slope and Systemic Inventory Level), which provide a clear, comprehensive and structured assessment of the SC performance at systemic level and the "internal process efficiency", as well as provide information on the potential benefits of partnerships, collaboration and information productivity of SC members (Cannella et al. 2013).

Due to the exploratory nature of this research, we adopt an appropriate and structured methodology for studying the dynamic of SCs, i.e., computer simulation (Oliveira et al. 2016), and more specifically the Multi-Agent Systems (MAS) modelling approach (Chatfield et al. 2006, Rahmandad and Sterman 2008). MAS has been recognized as a useful methodology to perform complex prospective SC analysis, and findings obtained with its proper adoption have been significantly contributing to understand the dynamics in SC (see e.g., Swaminathan et al. 1998, Long and Zhang 2014, Hilletofth et al. 2016 or Ponte et al. 2017). In order to perform a systematic simulation analysis we adopt reasonable assumptions and data inputs for simulations obtained from different cases to emulate real-world logistic systems (Rabinovic and Cheon 2011, Cannella et al. 2017). 
The results obtained reveal new insights on the impact of IS in SC by showing the need of individually estimating the potential value of retailers' information prior to the implementation of IS. When retailers are homogeneous, their collaboration may provide equal potential benefits to SC performance (they contribute the same to improve SC performance when they are involved in IS). Under this hypothesis, benefits of IS increase with the number of retailers involved and a full IS approach is recommended. On the contrary, when retailers are heterogeneous they have different potential value depending on their operational configuration. Under this hypothesis, performance achieved by different partial IS structures with the same number of retailers might be significantly different (e.g., we found that involving half of the total number of retailers into IS may lead to obtain over $70 \%$ of the total benefits of a FIS under the boundary conditions). In fact, retailers with (1) higher demand variance, (2) lower forecasting period, and (3) higher average lead time, are potentially the most beneficial partners when implementing IS.

The remainder of this paper is as follows: Section 2 describes the SC model and methodology. Section 3 presents the design of experiments and performance metrics. Section 4 analyses the results obtained. Section 5 presents managerial implications. Finally, Section 6 draws the conclusions, limitations of the study and future research lines.

\section{SC MODEL AND METHODOLOGY}

In order to analyse the partial IS scenarios, we develop a SC model to conduct the experiments. In SC dynamics literature, the most used SC model is the four-echelon serial SC (see e.g. Sterman 1989, Chatfield et al. 2004, Croson et al. 2014, Cannella et al. 2015). Echelons are referred as Factory $(i=1)$, Distributor $(i=2)$, Wholesaler $(i=3)$, and Retailer $(i=4)$. In order to analyse scenarios where only some of the retailers participate in IS (referred as partial IS) we extend this SC model by increasing the number of retailers to four, thus resulting a divergent SC (Lau et al. 2004, Dominguez et al. 2015a, Rached et al. 2016), as shown in Figure 1. 
Dominguez R., Cannella S., Póvoa A.P., Framinan J.M. 2017. Information sharing in supply chains with heterogeneous retailers. Omega. DOI: https://doi.org/10.1016/j.omega.2017.08.005

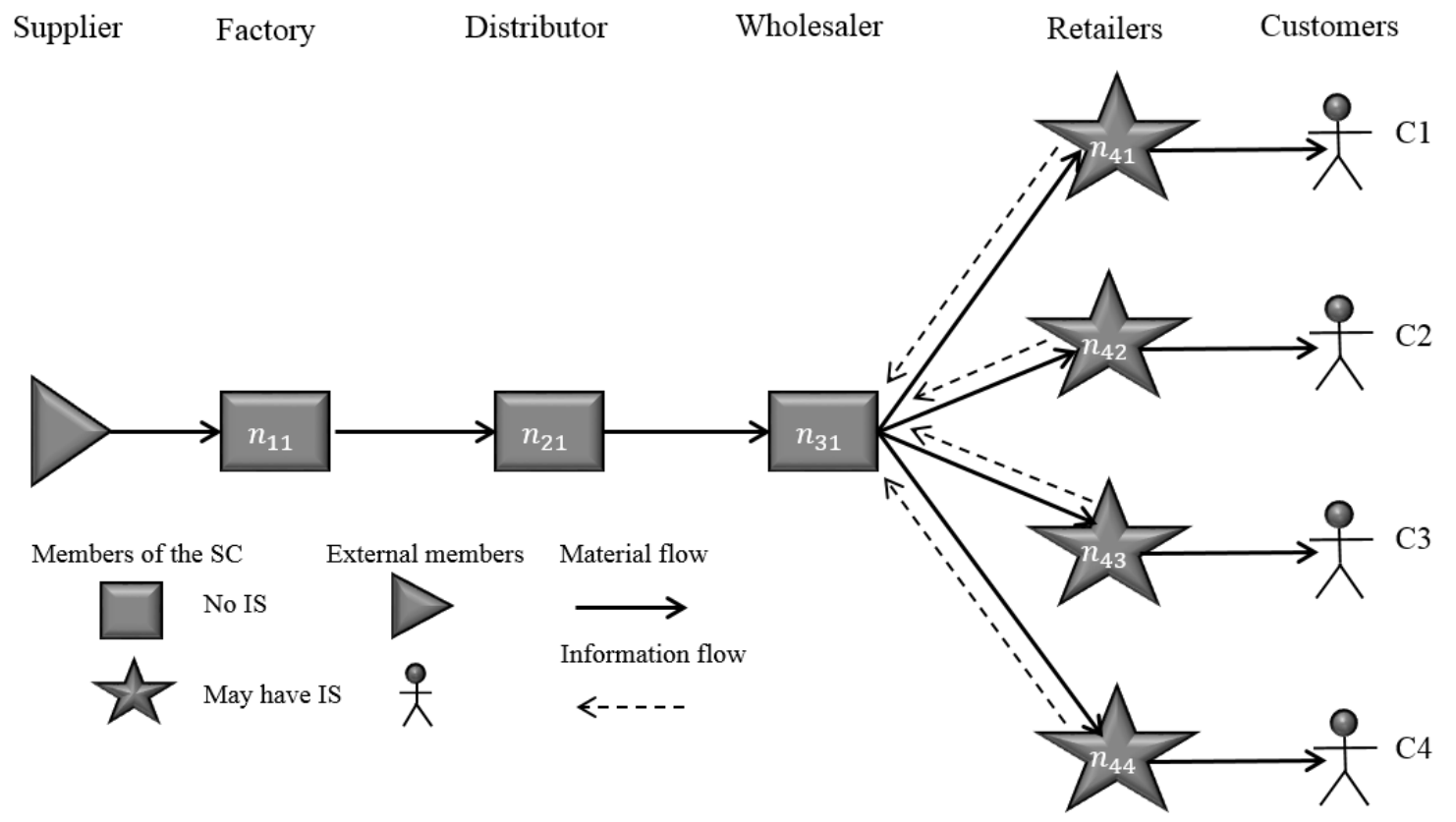

Figure 1. SC configuration.

In addition, we make the following assumptions regarding IS:

1. As we focus our analysis of partial IS at retailers' stage, only retailers share information on customer's demand.

2. Assuming that, due to some barriers (as described in Section 1) each enterprise is willing to share its local information only to its immediate upstream enterprise (see Lau et al. 2004, Kembro and Selviaridis 2015, for similar assumptions), only the wholesaler will be able to receive information from retailers.

\subsection{Supply Chain model}

The SC general model has been adapted from Chatfield et al. (2004) so as to model a generic divergent SC (Dominguez et al. 2015a,b, Cannella et al. 2017) and to include partial IS (i.e., any node at any echelon of the SC may share information with an upstream linked node). The notation is described in Table 1. This general model is adapted in Section 3.1 for the SCs under study with specific parameters values and experimental factors. 
Dominguez R., Cannella S., Póvoa A.P., Framinan J.M. 2017. Information sharing in supply chains with heterogeneous retailers. Omega. DOI: https://doi.org/10.1016/j.omega.2017.08.005

Table 1. Notation.

\begin{tabular}{|c|c|c|c|}
\hline$i$ & Echelon position in the SC & $\tau_{i j}$ & Forecasting period of $n_{i j}$ \\
\hline$j$ & Node position within a given echelon & $O_{i j}^{t}$ & Orders placed by $n_{i j}$ at time $t$ \\
\hline$n_{i j}$ & Node at position $j$ in echelon $i$ & $I_{i j}^{t}$ & Inventory on hand of $n_{i j}$ at time $t$ \\
\hline E & Total number of echelons & $W I P_{i j}^{t}$ & Work in progress of $n_{i j}$ at time $t$ \\
\hline$N_{i}$ & Total number of nodes in echelon $i$ & $B_{i j}^{t}$ & Backlog of $n_{i j}$ at time $t$ \\
\hline$N_{C}$ & Total number of customers & $S h D_{i j}^{t}$ & Shared demand of $n_{i j}$ at time $t$ \\
\hline$C_{j}$ & Customer at position $j$ & $\delta_{i j}$ & $\delta_{i j}=1$ if $n_{i j}$ is involved in IS, 0 otherwise." \\
\hline$t$ & Current simulation time & $I P_{i j}$ & Inventory policy of $n_{i j}$ \\
\hline$T$ & Total simulation time (excluding warm-up) & $V_{i j}$ & Set of downstream linked partners of $n_{i j}$ \\
\hline$D_{C_{j}}^{t}$ & Demand placed by customer $C_{j}$ at time $t$ & $s_{O_{i}^{t}}^{2}$ & Estimated variance of orders placed by echelon $i$ \\
\hline$\mu_{D_{C_{j}}}$ & Average demand placed by $C_{j}$ & $\bar{O}_{i}^{t}$ & $\begin{array}{l}\text { Estimated average of orders placed by echelon } i \text { at } \\
\text { time } t\end{array}$ \\
\hline $\bar{D}_{C_{j}}^{t}$ & $\begin{array}{l}\text { Estimated average demand placed by } C_{j} \text { at } \\
\text { time } t\end{array}$ & $\sigma_{O_{i j}}^{2}$ & Variance of orders placed by $n_{i j}$ \\
\hline$\sigma_{D_{C_{j}}}^{2}$ & Variance of demand placed by $C_{j}$ & $s_{O_{i j}^{t}}^{2}$ & Estimated variance of orders placed by $n_{i j}$ \\
\hline$s_{D_{C_{j}}^{t}}^{2}$ & Estimated variance demand placed by $C_{j}$ & $s_{I_{i}^{t}}^{2}$ & Estimated variance of inventory at echelon $i$ \\
\hline$D_{i j}^{t}$ & Demand faced by $n_{i j}$ at time $t$ & $\bar{I}_{i}^{t}$ & $\begin{array}{l}\text { Estimated average of inventory at echelon } i \text { at } \\
\text { time } t\end{array}$ \\
\hline $\bar{D}_{i j}^{t}$ & $\begin{array}{l}\text { Estimated average demand faced by } n_{i j} \text { at } \\
\text { time } t\end{array}$ & $s_{I_{i j}^{t}}^{2}$ & Estimated variance of inventory at $n_{i j}$ \\
\hline$s_{D_{i j}^{t}}^{2}$ & $\begin{array}{l}\text { Estimated variance demand faced by } n_{i j} \text { at } \\
\text { time } t\end{array}$ & $\bar{I}_{i j}^{t}$ & Estimated average of inventory at $n_{i j}$ at time $t$ \\
\hline$L_{i j}^{t}$ & Lead time of $n_{i j}$ at time $t$ & $\bar{D}_{C}^{t}$ & $\begin{array}{l}\text { Estimated average demand placed by customers at } \\
\text { time } t\end{array}$ \\
\hline$\mu_{L_{i j}}$ & Average lead time of $n_{i j}$ & $\pi_{i}$ & Position of the i-th echelon \\
\hline $\bar{L}_{i j}^{t}$ & Estimated average lead time of $n_{i j}$ at time $t$ & $O R V r R_{i}$ & Order Rate Variance Ratio echelon $i$ \\
\hline$\sigma_{L_{i j}}^{2}$ & Variance of the lead time of $n_{i j}$ & $\operatorname{InvVr} R_{i}$ & Inventory Variance Ratio echelon $i$ \\
\hline$S_{L_{i j}^{t}}^{2}$ & $\begin{array}{l}\text { Estimated variance of the lead time of } n_{i j} \text { at } \\
\text { time } t\end{array}$ & $\operatorname{InvAv} v_{i}$ & Inventory Average at echelon $i$ \\
\hline$R$ & Inventory review period & $B w S l$ & Bullwhip slope \\
\hline$S_{i j}^{t}$ & Desired level of stock of $n_{i j}$ at time $t$ & $\operatorname{InvSl}$ & Inventory slope \\
\hline$z$ & Safety factor for the OUT policy & $\operatorname{Sys} \operatorname{In} v A v$ & Systemic inventory average \\
\hline
\end{tabular}

\section{General Modelling Assumptions}

- At period $t$, each customer $C_{j}$ places an independent stochastic demand $D_{C_{j}}^{t}$ following a normal distribution with mean $\mu_{D_{C_{j}}}$, estimated by $\bar{D}_{C_{j}}^{t}$, and variance $\sigma_{D_{C_{j}}}^{2}$, estimated by $s_{D_{C_{j}}^{t}}^{2}$. Customers do not fill orders. 
- The factory places orders to an outside supplier with unlimited capacity.

- Stocking and transportation capacities are unlimited.

- The demand received by node $n_{i j}\left(D_{i j}^{t}\right)$, with mean estimated by $\bar{D}_{i j}^{t}$ and variance estimated by $s_{D_{i j}^{t}}^{2}$, equals the total orders received by downstream (linked) partners (denoted by $V_{i j}$ ), i.e., $D_{i j}^{t}=\sum_{r \in V_{i j}} O_{i+1, r}^{t}$. Demand received by retailers is customer demand $D_{E j}^{t}=D_{C_{j}}^{t}$.

- When the stock is not enough to fill an order completely there is a stock-out situation and partial replenishment is used (Chatfield et al. 2004).

- If a stock-out situation at the retailers' echelon occurs, we assume that backordering is not allowed and unfilled demand is lost. However, true demand received at retailers is recorded $\left(D_{C_{j}}^{t}\right)$, and shared with the upstream partner in case of participating in IS (see a detailed description of IS below) (Chatfield et al. 2004, Agrawal et al. 2009, Choudhary and Shankar 2015). Upstream members of the SC are allowed to backorder.

- We assume that returns of excess inventory to upstream partners are not permitted since the allowance of returns, although a common assumption in the bullwhip effect literature, may not be realistic and may overestimate the bullwhip effect (Chatfield and Pritchard 2013, Dominguez et al. 2015b).

\section{$\underline{\text { Lead Times }}$}

Lead times $\left(L_{i j}^{t}\right)$ are defined as the time elapsed between order and receipt, and may include manufacturing time, shipment to port, ship transit time, unloading, transfer to rail and/or truck, etc. (Disney et al. 2016). We assume stochastic lead times, which are stationary, independent, and identically distributed. In line with previous literature works and industrial data sets, lead times are assumed to follow a Gamma distribution (Chatfield et al. 2004, Kim et al. 2006, Hayya et al. 2011, Chatfield and Pritchard 2013, Bischak et al. 2014, Dominguez et al. 2015b, Cannella et al. 2017, among others) with mean $\mu_{L_{i j}}$ and variance $\sigma_{L_{i j}}^{2}$. Since we use a periodic Order-Up-To (OUT) replenishment policy (see below), and this policy operates on a discrete time basis, lead times must be integers (Disney et al. 2016, Wang and Disney 2017). Therefore, values obtained from the Gamma distribution are discretized. Consequently, each time an order is generated, 
a random integer lead time is assigned to it, which corresponds to the number of periods required for the order to arrive.

Finally, note that uncertain lead times often lead to a phenomenon called order crossovers (Kim et al. 2006, Hayya et al. 2008, Bischak et al. 2014), i.e., replenishment may be received in a different sequence than they were ordered (Wang and Disney 2017). Therefore, a node may receive more than one order in some periods, and receive no orders in other periods (Disney et al. 2016).

\section{OUT replenishment policy}

All SC members use a $(R, S)$ or periodic review with OUT level (Nachtmann et al. 2010, Chatfield and Pritchard 2013, Li et al. 2014). Even though OUT policies are not optimal when orders may crossover (see Srinivasan et al. 2011, where authors show that, in the presence of order crossovers, the optimal policy for periodic review systems with variable lead times is state dependent and thus, computationally intractable; and Disney et al. 2016, where authors found a linear policy that outperforms the OUT policy in the presence of order crossovers), they are widely used in SC practice to facilitate the coordination of product flows, and in the research literature since it is well understood and implementable (Bischak et al. 2014).

The OUT level $\left(S_{i j}^{t}\right)$ is the base stock that allows the system to meet the demand during the period $L_{i j}^{t}+R$ or "protection period" (Chatfield et al. 2004). Under this policy, orders $\left(O_{i j}^{t}\right)$ are placed at discrete time intervals $R$ in order to raise the current inventory position $\left(I P_{i j}^{t}\right)$ to the target inventory level $S_{i j}^{t}$ (Equation (1)). The inventory position equals the net stock plus the inventory on order but not yet arrived, or work in progress $\left(W I P_{i j}^{t}\right)$ (Disney and Lambrecht 2008, Li et al. 2014). The net stock equals current on hand inventory $\left(I_{i j}^{t}\right)$ minus backlog $\left(B_{i j}^{t}\right)$, with the exception of retailers, which are not allowed to backorder (Equation (2)). Since returns are not allowed as well, orders are truncated to zero (Equation (3)).

$$
\begin{gathered}
O_{i j}^{t}=S_{i j}^{t}-I P_{i j}^{t}=S_{i j}^{t}-I_{i j}^{t}+B_{i j}^{t}-W I P_{i j}^{t} ; \forall i<E \\
B_{E j}^{t}=0
\end{gathered}
$$




$$
O_{i j}^{t} \geq 0
$$

To increase the generality of this research and to add up on published works, we have decided to adopt two emblematic OUT approaches, namely $S 1$ and $S 2$. $S_{i j}^{t}$ may be calculated using any of these two approaches (Equations (4) and (5)), where $z$ is a safety factor, $\bar{L}_{i j}^{t}$ is the estimation of the average lead time and $s_{L_{i j}^{t}}^{2}$ is the estimation of its variance (for convenience and without loss of generality, we assume the same $z$ for all nodes of the SC (Kim et al. 2006)). Both approaches are service level oriented (i.e., it is assumed that nodes are willing to maintain a high service level). S1 is a common practice based on a deterministic lead times. $S 2$ is also a popular approach (Disney et al. 2016), and it has been used in several studies with stochastic lead times (see e.g. Chatfield et al. 2004, Nachtmann et al. 2010, Chatfield et al. 2013, Chatfield and Pritchard 2013, Bischak et al. 2014, Dominguez et al. 2015b, Cannella et al. 2017, among others). Thus both practices are adopted for benchmarking.

$$
\begin{gathered}
S 1=S_{i j}^{t}=\left(\bar{L}_{i j}^{t}+R\right) \bar{D}_{i j}^{t}+z \sqrt{\left(\bar{L}_{i j}^{t}+R\right)} s_{D_{i j}^{t}} \\
S 2=S_{i j}^{t}=\left(\bar{L}_{i j}^{t}+R\right) \bar{D}_{i j}^{t}+z \sqrt{\left(\bar{L}_{i j}^{t}+R\right) s_{D_{i j}^{t}}^{2}+\bar{D}_{i j}^{t}{ }^{2} s_{L_{i j}^{t}}^{2}}
\end{gathered}
$$

\section{Forecasting}

In order to update $S_{i j}^{t}$, node $n_{i j}$ dynamically updates, in each period, the forecast of incoming demand (i.e., expected average $\bar{D}_{i j}^{t}$ and variance $s_{D_{i j}^{t}}^{2}$ ) and lead time of the upstream partner (i.e., expected average, $\bar{L}_{i j}^{t}$ and variance $s_{L_{i j}^{t}}^{2}$ ). To estimate $\bar{D}_{i j}^{t}$, node $n_{i j}$ uses a $\tau_{i j}$-periods moving averages forecasting technique, commonly used in practice (Chen et al. 2000, Disney and Lambrecht 2008). With this technique, demand is estimated by averaging the demand received during the most recent $\tau_{i j}$ periods (Equation (6)). A high value of $\tau_{i j}$ delivers a more stable forecast pattern (closer to the average demand), while a low value of $\tau_{i j}$ results in a more nervous forecast pattern (closer to the real demand) (Chase et al. 2004). Similarly, $s_{D_{i j}^{t}}^{2}$ is estimated using a $\tau_{i j^{-}}$ period moving variances (Equation (7)). Finally, $\bar{L}_{i j}^{t}$ and $s_{L_{i j}^{t}}^{2}$ are estimated with running 
averages and variances, i.e., using all prior information available instead of only the most recent $\tau_{i j}$ periods (Chatfield 2013, Cannella et al. 2017).

$$
\begin{gathered}
\bar{D}_{i j}^{t}=\frac{\sum_{k=1}^{\tau_{i j}} D_{i j}^{t-k}}{\tau_{i j}} \\
s_{D_{i j}^{t}}^{2}=\frac{1}{\tau_{i j}-1} \sum_{k=1}^{\tau_{i j}}\left(D_{i j}^{t-k}-\bar{D}_{i j}^{t-k}\right)^{2}
\end{gathered}
$$

\section{Information sharing}

Information sharing considers that a node $n_{i j}$ may receive demand information from downstream linked nodes. The information received by a node $n_{i j}$ is modelled in a divergent SC by the variable $S h D_{i j}^{t}$ (shared demand) (Dominguez et al. 2014), defined through Equation (8). This equation considers that: if downstream partners of $n_{i j}(j \in$ $\left.V_{i j}\right)$ do not participate in IS, $S h D_{i j}^{t}$ equals the total incoming orders of $n_{i j}\left(S h D_{i j}^{t}=\right.$ $D_{i j}^{t}$ ); if downstream partners of $n_{i j}$ participate in IS, $S h D_{i j}^{t}$ equals their total demand; if there is a mixture of participants/not participants downstream partners of $n_{i j}$ in IS, $S h D_{i j}^{t}$ is the sum of incoming orders placed by non-participant downstream partners of $n_{i j}$ and demand faced by participants downstream partners of $n_{i j}$. In order to model this partial IS condition we use a binary variable $\left(\delta_{i j}\right): \delta_{i j}=1$ if a node $n_{i j}$ shares information with an upstream partner, and $\delta_{i j}=0$ otherwise. A node $n_{i j}$ uses this information to compute the OUT level and to forecast demand, replacing the variable $D_{i j}^{t}$ by $S h D_{i j}^{t}$ in Equations (4), (5), (6) and (7).

$$
S h D_{i j}^{t}=\sum_{r \in V_{i j}} D_{i+1, r}^{t} \delta_{i+1, r}+O_{i+1, r}^{t}\left(1-\delta_{i+1, r}\right)
$$

\section{Sequence of actions}

The sequence of events is based on that of Chatfield et al. (2004). A node $n_{i j}$ at the beginning of period $t$ updates the order-up-to level $\left(S_{i j}^{t}\right)$ and places an order to rise up the inventory position to this level. As in Chatfield et al. (2004), we assume that all 
nodes perform these actions in parallel, thus they are not aware of what is occurring at the other nodes. Therefore, information on orders, shared demand and lead times at period $t$ is not available to update $S_{i j}^{t}$, and nodes use data from previous period $t$-1 (we are assuming $R=1$, see Section 3.1) to forecast demand and lead times, and update $S_{i j}^{t}$. Then, new products are received from the upstream partner, and backlog and the new incoming demand are satisfied. This modelling assumption is also consistent with Chen et al. (2000). A summary of the sequence of events is shown next:

1. Update the OUT level $\left(S_{i j}^{t}\right)$ using the forecasts computed in the previous period.

2. If $S_{i j}^{t}$ is higher than the inventory position, place an order $O_{i j}^{t}$ to raise the inventory position to $S_{i j}^{t}$ and increase $W I P_{i j}^{t}$ accordingly. Otherwise, no order is placed.

3. Receive products from the upstream partner. Reduce $W I P_{i j}^{t}$ and increase $I_{i j}^{t}$ accordingly.

4. If $i<4$ and $I_{i j}^{t}>0$, satisfy backorders. Reduce $I_{i j}^{t}$ and $B_{i j}^{t}$ accordingly.

5. Receive new orders from downstream nodes and satisfy demand if possible, reducing $I_{i j}^{t}$ accordingly. If $i<4$, any unsatisfied demand is backordered, and $B_{i j}^{t}$ is increased accordingly. Otherwise, unsatisfied demand is lost.

6. Update $S h D_{i j}^{t}$ and calculate a new forecast to be used in the next period $\left[\overline{S h D}_{i j}^{t}, s_{S h D_{i j}^{t}}^{2}, \bar{L}_{i j}^{t}, s_{L_{i j}^{t}}^{2}\right]$.

\subsection{Methodology}

The inherent complexity of the SCs under analysis (such as the divergent configuration, partial IS, or stochastic demands and lead times) makes simulation to be a good approach to infer on bullwhip effect. More specifically, we use SCOPE (Dominguez and Framinan 2013, Dominguez et al. 2015b), a MAS-based SC simulator specifically designed to model complex SCs that was implemented through Java-Swarm (Hiebeler 1994, Minar et al. 1996), a toolbox library for MAS development.

Real SCs have multiple layers of abstraction (Lin et al. 2002) and they can be studied in different levels of detail. Accordingly, SCOPE was developed adopting a two-layer 
design: an Enterprise Layer containing all enterprises in the SC, and a Functional Layer, including the main functions/departments of the enterprises. The Enterprise Layer is modelled by one generic and reusable agent (Enterprise Agent), and enterprises are built up as instances of this agent. The behaviour of the Enterprise Agent can be customized according to the role that the enterprise plays in the SC. This customization is made by means of functional agents (Functional Layer), who are in charge of the physical and planning tasks carried out by the enterprise, thus building a nested agent structure as shown in Figure 2. The collection of functional agents was designed according to the Level 1 of the Supply Chain Operations Reference (SCOR) model (Supply Chain Council 2006) and the Supply Chain Planning Matrix (Stadtler 2005), resulting in a total of 9 functional agents: Source Agent, Make Agent and Deliver Agent, Demand Fulfilment Agent, Demand Forecast Agent, Master Planning Agent, Production Planning Agent, Material Resource Planning (MRP) Agent and Scheduling Agent.

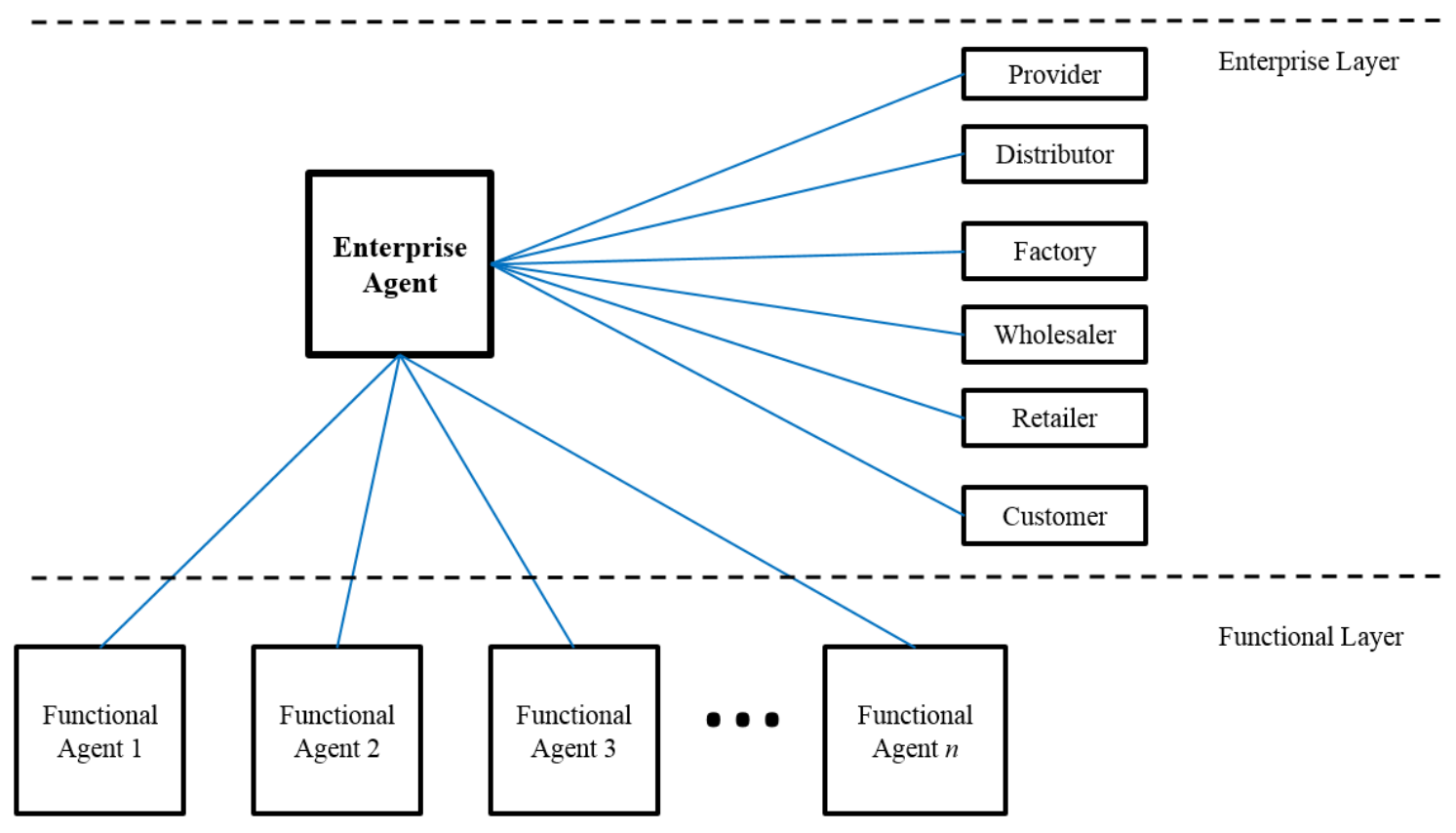

Figure 2. SCOPE framework.

Due to the scalability of MAS models, SCOPE allows to create any number of companies distributed along any number of different echelons, as required by the user (see e.g., Dominguez et al. 2015a). Companies can be linked to any other partner/s in the SC, thus allowing to create a wide range of SC configurations (e.g. divergent, 
convergent, conjoined or a more generic network SC). Also, they can be easily customized, allowing the user to create SCs with different members (heterogeneous SCs). Additional features of SCOPE are: (1) the use of random variables allows to simulate stochasticity in any business process; (2) its modular design and its codification in Java make possible to easily add new functions and behaviours, or modify existent ones; (3) all variable are accessible after simulation, thus allowing to analyse the outputs of interest.

All the above features make SCOPE a good choice to model divergent SC with heterogeneous companies, stochastic processes and partial IS. SCOPE was validated by contrasting the results obtained by other authors, such as Chen et al. (2000), Dejonckheere et al. (2004) and Chatfield et al. (2004) (see Dominguez and Framinan 2013).

\section{DESIGN OF EXPERIMENTS (DoE)}

The aim of the DoE is to analyse scenarios of partial IS at retailers, assessing how different partial IS structures (i.e., which retailers are sharing information with the wholesaler) impact SC performance over a variety of retailers' operational configurations. To do so, we consider two different cases (Huang and Iravani 2005): (1) homogeneous retailers (retailers' operational configurations are identical); (2) heterogeneous retailers (retailers' operational configurations are different). In the following we describe the OFs that characterize the different retailers' operational configurations, the specific model and simulation parameters, the three metrics used to measure SC performance, and the DoE.

\subsection{Operational factors and model parameters}

We characterize retailers' operational configuration by four OFs, i.e., demand variance $\left(\sigma_{D_{C_{j}}}^{2}\right)$, forecasting period $\left(\tau_{i j}\right)$, lead time average $\left(\mu_{L_{i j}}\right)$ and inventory policy $\left(I P_{i j}\right)$. In order to provide comprehensive data inputs, we adopt a full-factorial experimental design (Evers and Wan 2012), which is described in the following sections. We select two levels for each retailers' OF, namely Low $(O F L)$ and high $(O F H)$, which represent 
extreme values of the factors (Costantino et al. 2014, Cannella et al. 2017). These values are chosen according to two principles:

(1) In order to satisfy the hypothesis of heterogeneous retailers, $O F L$ and $O F H$ need to be significantly different.

(2) In order to produce comparable results, $O F L$ and $O F H$ need to adopt values from other similar studies in SC dynamic literature.

$O F H$ values for $\sigma_{D_{C_{j}}}^{2}, \tau_{i j}$, and $\mu_{L_{i j}}$, can be found in Chatfield et al. (2004), Chatfield et al. (2013), Costantino et al. (2014) and Dominguez et al. (2015b). OFL values of these factors are obtained by significantly reducing the $O F H$ values. For $I P_{i j}, O F H$ is set to $S 2$ (see e.g. Chatfield et al. 2004, Nachtmann et al. 2010, Chatfield et al. 2013, Dominguez et al. 2015b), while $O F L$ is set to $S 1$ (see e.g. Chatfield et al. 2004, Dominguez et al. 2014, Costantino et al. 2014). This is an arbitrary choice without impact in the results. These values can be found in Table 2.

Table 2. Operational factors, model parameters, simulation parameters and performance metrics.

\begin{tabular}{|c|c|c|c|}
\hline \multirow{2}{*}{ OFs } & \multicolumn{2}{|c|}{ Retailers } & \multirow{2}{*}{$\begin{array}{l}\text { Upstream } \\
\text { Members }\end{array}$} \\
\hline & Low $(O F L)$ & $\operatorname{High}(O F H)$ & \\
\hline Demand variance $\left(\sigma_{D_{C_{j}}}^{2}\right)$ & $100\left(\sigma_{D_{C_{j}}}=10\right)$ & $400\left(\sigma_{D_{C_{j}}}=20\right)$ & N.A. \\
\hline Forecasting period $\left(\tau_{i j}\right)$ & 5 & 15 & 15 \\
\hline Lead time average $\left(\mu_{L_{i j}}\right)$ & 2 & 4 & 2 \\
\hline Inventory policy $\left(I P_{i j}\right)$ & $S 1$ & $S 2$ & $S 1$ \\
\hline General model parameters & Value & Simulation parameters & Value \\
\hline Demand average $\left(\mu_{D_{C_{j}}}\right)$ & 50 & Simulation time $(T)$ & 4000 \\
\hline Lead time c.v. $\left(\sigma_{L_{i j}} / \mu_{L_{i j}}\right)$ & 0.50 & Warm-up & 1000 \\
\hline Review period $(R)$ & 1 & Number of replications & 20 \\
\hline Safety factor $(z)$ & 2 & \multicolumn{2}{|c|}{ Performance Metrics } \\
\hline Echelon position $(i)$ & $i=1 \ldots 4$ & \multicolumn{2}{|c|}{$B w S l$} \\
\hline \multirow[t]{2}{*}{ Node position in echelon $i(j)$} & $j=1 \quad \forall i<4$ & \multicolumn{2}{|c|}{$\operatorname{InvSl}$} \\
\hline & $j=1 \ldots 4 \forall i=4$ & \multicolumn{2}{|c|}{ SysInvAv } \\
\hline \multirow[t]{2}{*}{$\operatorname{IS}\left(\delta_{i j}\right)$} & $\delta_{i j}=0 \forall i<4$ & & \\
\hline & $\delta_{i j}=0,1 \forall i=4$ & & \\
\hline
\end{tabular}


Upstream members of the SC (i.e., Wholesaler, Distributor and Factory) are not subject of analysis in this work. Hence we simplify the DoE by maintaining the operational configuration of these members fixed in all experiments (Table 2).

The parameters of the general model -summarised in Table 2- are chosen as usual values used in SC dynamics literature (see, e.g., Chatfield 2013, Chatfield and Pritchard 2013, Costantino et al. 2014, Dominguez et al. 2015a). The value of the safety factor $(z=2)$ corresponds with a customer service level of $97.72 \%$ when using the normal approximation.

In order to adapt the model presented in Section 2.1 to the divergent SC under study (Figure 1), we establish the boundaries of $\delta_{i j}$ and subscripts $i$ and $j$, as in Table 2.

\subsection{Simulation parameters}

Uncertainty is inherent to many of the SC's processes (Heckmann et al. 2015). In order to account for randomness, multiple replications of the experiments were performed, and the simulation outputs were statistically analysed. According to Kelton et al. (2007), when the half-width of confidence interval is smaller than a user-specified value (e.g. within $10 \%$ of the mean, Yang et al. 2011), the number of replications is acceptable for statistical analysis. As suggested by these authors, simulations were first conducted with 10 replications. Due to the use of systemic performance metrics (see Section 3.3), we obtained results with very low variances, and thus the half width was below $10 \%$ of the average in all cases. Even though, in order to increase precision of results, we have performed 20 replications of each experiment (see e.g. Nair and Vidal 2011, Yang et al. 2011).

Total simulation time ( $T$ ) was set to 4,000 periods to ensure that a steady state of the system is reached. Also, the first 1,000 periods were removed from the results, as a warm-up time, to eliminate system's initialization effects.

\subsection{Performance metrics}

In order to capture the dynamics of the SC, we adopt a structured non-financial performance measurement system, given by three common metrics, namely: Order 
Variance Ratio, Inventory Variance Ratio and Inventory Average (see e.g. Cannella et al. 2013, Costantino et al. 2014, Wang and Disney 2016, among others). These metrics are computed at echelon's level. Due to the high number of SCs that result from the DoE (see Section 3.4), we focus instead on the global performance of the SC, allowing for an easy comparison among the different SCs (Cannella et al. 2017). To do so, we use systemic metrics (i.e., SC-level metrics), which are computed from their corresponding echelon's metrics, i.e., Bullwhip Slope, Inventory Slope, and Systemic Inventory Average, respectively. A reduction of this set of metrics reflects improved cost effectiveness of members' operations. They provide a comprehensive and structured assessment of the internal process efficiency of the SC at systemic level and provide information on the potential benefits of partnerships, collaboration and information productivity of SC members (Cannella et al. 2013). A detailed description of each metric is provided below.

\subsubsection{Order Rate Variance Ratio - Bullwhip Slope}

At echelon's level, Order Rate Variance Ratio $\left(O R V r R_{i}\right)$ accounts for order variance amplification upstream in the SC. In the long-term run it is computed as $O R V r R_{i}=$ $s_{O_{i}^{T}}^{2} / s_{D_{C}^{T}}^{2}$ (Chen et al. 2000, Chatfield et al. 2004, Dejonckheere et al. 2004). In order to apply this metric to a divergent SC, we use aggregate measures for each echelon (Dominguez et al. 2015b). Therefore, assuming that all customers' demands are independent and that each node places orders independently, we can aggregate order variances at each echelon and thus $O R V r R_{i}$ for a divergent SC can be written as in Equation (9):

$$
\operatorname{ORVrR} R_{i}=\frac{\sum_{j=1}^{N_{i}} s_{O_{i j}^{T}}^{2}}{\sum_{j=1}^{N_{C}} s_{D_{C_{j}}^{T}}^{2}}
$$

At system's level we use the Bullwhip Slope ( $B w S l$ ) (Cannella et al. 2013, Dominguez et al. 2015b). BwSl is computed as the slope of the linear interpolation of the set of $O R \operatorname{Vr} R_{i}$ values for a given SC (Equation (10)), where $\pi_{i}$ is the position of the $i$-th echelon in Dejonckheere's et al. curve. This metric measures the magnitude of the bullwhip propagation across the SC and allows for a concise and holistic comparison between different SCs. A high value of $B w S l$ indicates a fast propagation of the bullwhip effect through the SC, whereas a low value indicates a smooth propagation. 
$B w S l$ provides information on potential unnecessary costs for suppliers, such as lost capacity or opportunity costs, and on all other unexpected costs generated by the bullwhip effect (Cannella et al. 2013, Trapero and Pedregal 2016).

$$
B w S l=\operatorname{tg} \vartheta_{O R V R R}=\frac{E \sum_{i=1}^{E} \pi_{i} O R V r R_{i}-\sum_{i=1}^{E} \pi_{i} \sum_{i=1}^{E} O R V r R_{i}}{E \sum_{i=1}^{E} \pi_{i}^{2}-\left(\sum_{i=1}^{E} \pi_{i}\right)^{2}}
$$

\subsubsection{Inventory Variance Ratio - Inventory Slope}

At echelon's level, the Inventory Variance Ratio $\left(\operatorname{InvVr} R_{i}\right)$ (Disney and Towill 2003), assesses the stability degree of the inventory and it can be associated with the variation and the potential increment of the holding costs per unit (Cannella et al. 2015). It is computed as the ratio between the inventory variance at echelon $i$ and the customer demand variance: $\operatorname{Inv} \operatorname{Vr} R_{i}=\left(s_{I_{i}^{T}}^{2} / \bar{I}_{i}^{T}\right) /\left(s_{D_{C}^{T}}^{2} / \bar{D}_{C}^{T}\right)$. Following the same procedure as with $O R V r R_{i}$, we derive $\operatorname{InvVr} R_{i}$ for a divergent SC, resulting the expression shown in Equation (11).

$$
\operatorname{InvVrR} R_{i}=\frac{\sum_{j=1}^{N_{i}} s_{I_{i j}^{T}}^{2} / \sum_{j=1}^{N_{i}} \bar{I}_{i j}^{T}}{\sum_{j=1}^{N_{C}} s_{D_{C_{j}}^{T}}^{2} / \sum_{j=1}^{N_{C}} \bar{D}_{C_{j}}^{T}}
$$

At system's level we use the Inventory Slope (InvSl) (Cannella et al. 2013). This metric is similar to $\mathrm{BwSl}$ (Equation (12)), but accounts for inventory instability propagation across the SC. An increased InvSl results in higher holding and backlog costs, inflating the average inventory costs per period (Disney and Lambrecht 2008), increasing holding unit costs, missing production schedules, job sequencing and resource re-allocation (Cannella et al. 2013, Duong et al. 2015).

$$
\operatorname{InvSl}=\operatorname{tg} \vartheta_{\operatorname{InvVrR}}=\frac{E \sum_{i=1}^{E} \pi_{i} \operatorname{InvVr} R_{i}-\sum_{i=1}^{E} \pi_{i} \sum_{i=1}^{E} \operatorname{InvVr} R_{i}}{E \sum_{i=1}^{E} \pi_{i}^{2}-\left(\sum_{i=1}^{E} \pi_{i}\right)^{2}}
$$

\subsubsection{Inventory Average - Systemic Inventory Average}

At echelon's level, Inventory Average $\left(\operatorname{Inv} A v_{i}\right)$ can be associated to the average holding cost over the observation time (Cannella et al. 2013), and it is commonly used in production-distribution systems analysis to assess concise information on inventory investment (Cannella and Ciancimino 2010, Ganesh et al. 2014a). It can be viewed as a metric complementary to $\operatorname{InvVrR} R_{i}$. For a divergent SC this metric can be expressed as follows: 


$$
\operatorname{Inv} A v_{i}=\frac{\sum_{j=1}^{N_{i}} \sum_{t=1}^{T} I_{i j}^{t}}{T}
$$

At system's level we use the Systemic Inventory Average (SysInvAv) (Cannella et al. 2013). This metric accounts for the average inventory of the whole SC. As it is common to model holding costs as linearly dependent from stock levels (Sharma 2010, Cachon and Olivares 2010), this metric quantifies the average holding costs across the observation time (Cannella et al. 2013). Since all SCs under analysis have the same number of nodes, we can use the following expression:

$$
S y \operatorname{Inv} A v=\frac{\sum_{i=1}^{E} \sum_{j=1}^{N_{i}} \sum_{t=1}^{T} I_{i j}^{t}}{T}
$$

\subsection{Experiments}

We perform two sets of experiments. In the first one we assume homogeneous retailers, and intends to assess the contribution of each retailer involved in IS on improving SC performance when all of them have identical operational configurations. In order to increase the generality of results, we consider a wide range of possible operational configurations for the retailers by analysing the full factorial set of the OFs. Since each OF has two levels, we analyse $2^{4}$ different retailers' operational configurations. Then, each retailers' operational configuration is evaluated under five IS structures: (1) no IS (NIS), (2) 1 retailer shares information (1retIS), (3) 2 retailers share information (2retIS), (4) 3 retailers share information (3retIS), and (5) 4 retailers share information $(F I S)$. Therefore, we analyse a total of $5 \times 2^{4}=80$ SCs in this set of experiments.

The second set of experiments is performed under the hypothesis of heterogeneous retailers, and intends to assess the contribution of each retailer involved in IS on improving SC performance when they have different operational configurations, and how retailers' OFs may influence to their contribution. To this aim, for each of the four OFs, we model a set of SCs where there are two groups of two retailers. The two retailers in each group have the same $\mathrm{OF}$ value $\left(\mathrm{OF}=\mathrm{OF}^{*}\right.$ from now on), but the $\mathrm{OF}$ is different among the two groups. More specifically, the first pair of retailers have the $O F L$ value and the second pair have the $O F H$ value (e.g. if $\mathrm{OF}^{*}=\sigma_{D_{C_{j}}}^{2}$, then the first pair of retailers will have $\sigma_{D_{C_{j}}}^{2}=100$ and the second pair of retailers will have $\left.\sigma_{D_{C_{j}}}^{2}=400\right)$ ). The other three OFs remain the same for all the retailers. To increase the generality of the 
results, for a given $\mathrm{OF}=\mathrm{OF}^{*}$ we analyse the full factorial set of the other three OFs $\left(\mathrm{OF} \neq \mathrm{OF}^{*}\right)$. Therefore, we have a total of $4\left(\mathrm{OF}=\mathrm{OF}^{*}\right) \times 2^{3}\left(\mathrm{OF} \neq \mathrm{OF}^{*}\right)=32$ retailers' operational configurations. Finally, each retailers' operational configuration is evaluated under four IS structures: (1) NIS, (2) first pair of retailers share information (referred as OFLIS), (3) second pair of retailers share information (referred as OFHIS), and (4) FIS. We analyse a total of $4 \times 32=128$ SCs in this set of experiments. A summary of the DoE is presented in Table 3.

Table 3. Summary of experiments (DoE).

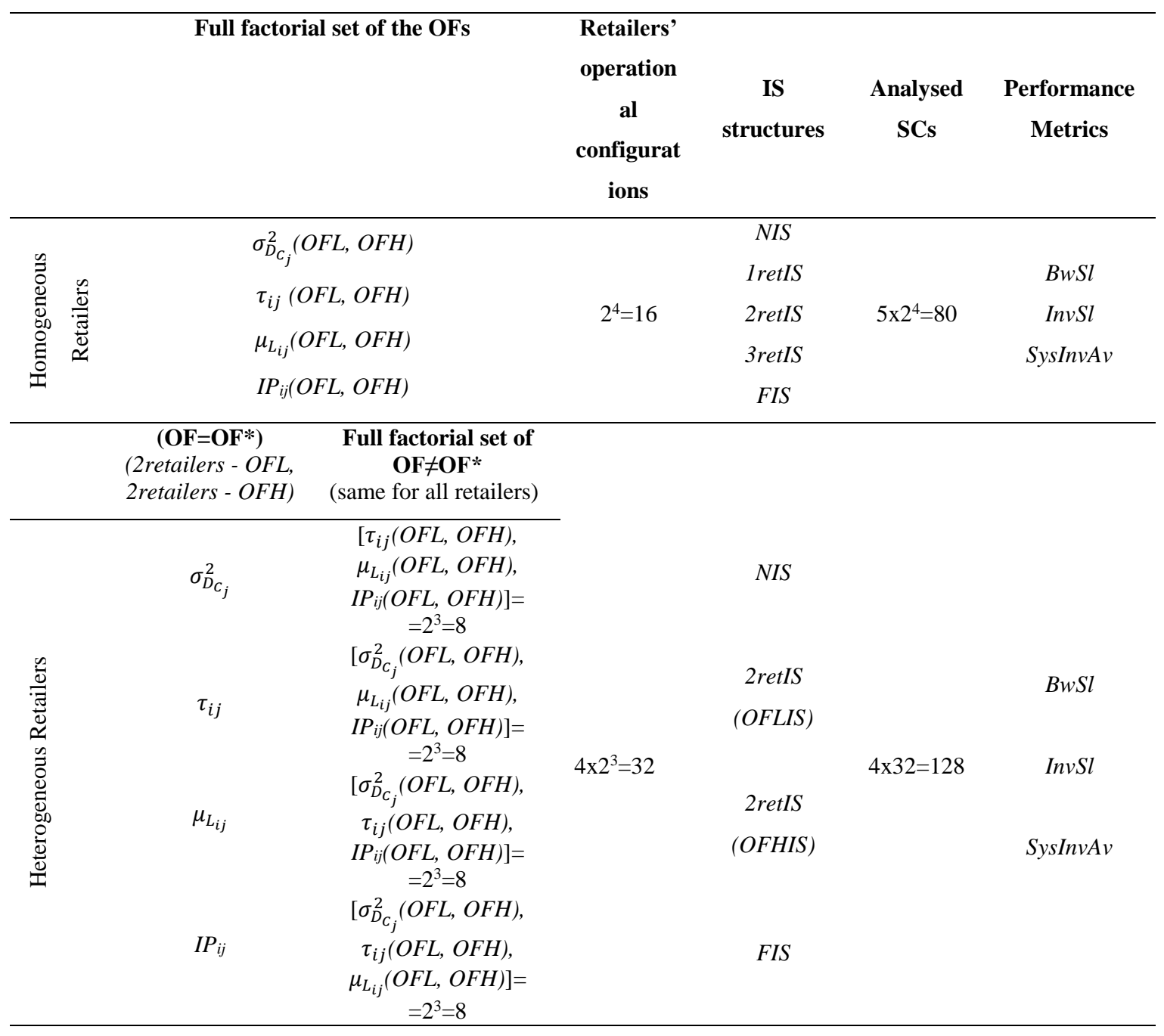

The simulations were performed on an Intel Core 2 Duo P8600 2.40GHz computer with 2GB RAM. The effective simulation time was 14 hours and 49 minutes for the set of homogeneous retailers (1,600 simulation runs), and 26 hours and 4 minutes for the set of heterogeneous retailers (2,560 simulation runs). 


\section{ANALYSIS OF RESULTS}

This section presents the results obtained by the simulations performed with SCOPE according to the DoE presented in Section 3. We also derive meaningful findings on the implementation of IS on a SC with several retailers.

\subsection{Homogeneous retailers}

Herein we present the results obtained for the set of experiments under the hypothesis of homogeneous retailers. Table 4 shows a legend, labelling the 16 retailers' operational configurations from \#1 to \#16. For each retailers' operational configuration, the SC is analysed under five IS structures (Table 3). The metrics obtained from all scenarios are averaged over the 20 replications, and results are plotted in Figure 3. For clarity, results obtained for each performance metric are divided in 4 plots. Also, they are displayed from the highest value of the metric to the lowest value of the metric.

Table 4. Retailers' operational configurations.

\begin{tabular}{|c|c|c|c|c|c|c|c|c|c|c|c|c|c|c|c|c|}
\hline $\begin{array}{c}H=\text { OFH } \\
L=\text { OFL }\end{array}$ & $\# 1$ & $\# 2$ & $\# 3$ & $\# 4$ & $\# 5$ & $\# 6$ & $\# 7$ & $\# 8$ & $\# 9$ & $\# 10$ & $\# 11$ & $\# 12$ & $\# 13$ & $\# 14$ & $\# 15$ & $\# 16$ \\
\hline$\mu_{L_{i j}}$ & $H$ & $H$ & $H$ & $H$ & $H$ & $H$ & $H$ & $H$ & $L$ & $L$ & $L$ & $L$ & $L$ & $L$ & $L$ & $L$ \\
\hline$I P_{i j}$ & $H$ & $H$ & $H$ & $H$ & $L$ & $L$ & $L$ & $L$ & $H$ & $H$ & $H$ & $H$ & $L$ & $L$ & $L$ & $L$ \\
\hline$\tau_{i j}$ & $H$ & $H$ & $L$ & $L$ & $H$ & $H$ & $L$ & $L$ & $H$ & $H$ & $L$ & $L$ & $H$ & $H$ & $L$ & $L$ \\
\hline$\sigma_{D_{C_{j}}}^{2}$ & $H$ & $L$ & $H$ & $L$ & $H$ & $L$ & $H$ & $L$ & $H$ & $L$ & $H$ & $L$ & $H$ & $L$ & $H$ & $L$ \\
\hline
\end{tabular}

Due to the use of system's metrics, the results obtained over the 20 replications are very close to the average with very low variances. To ensure the significance of results obtained we performed an ANOVA for each metric and each retailers' operational configuration. All tests were significant at the $95 \%$ confidence level. 


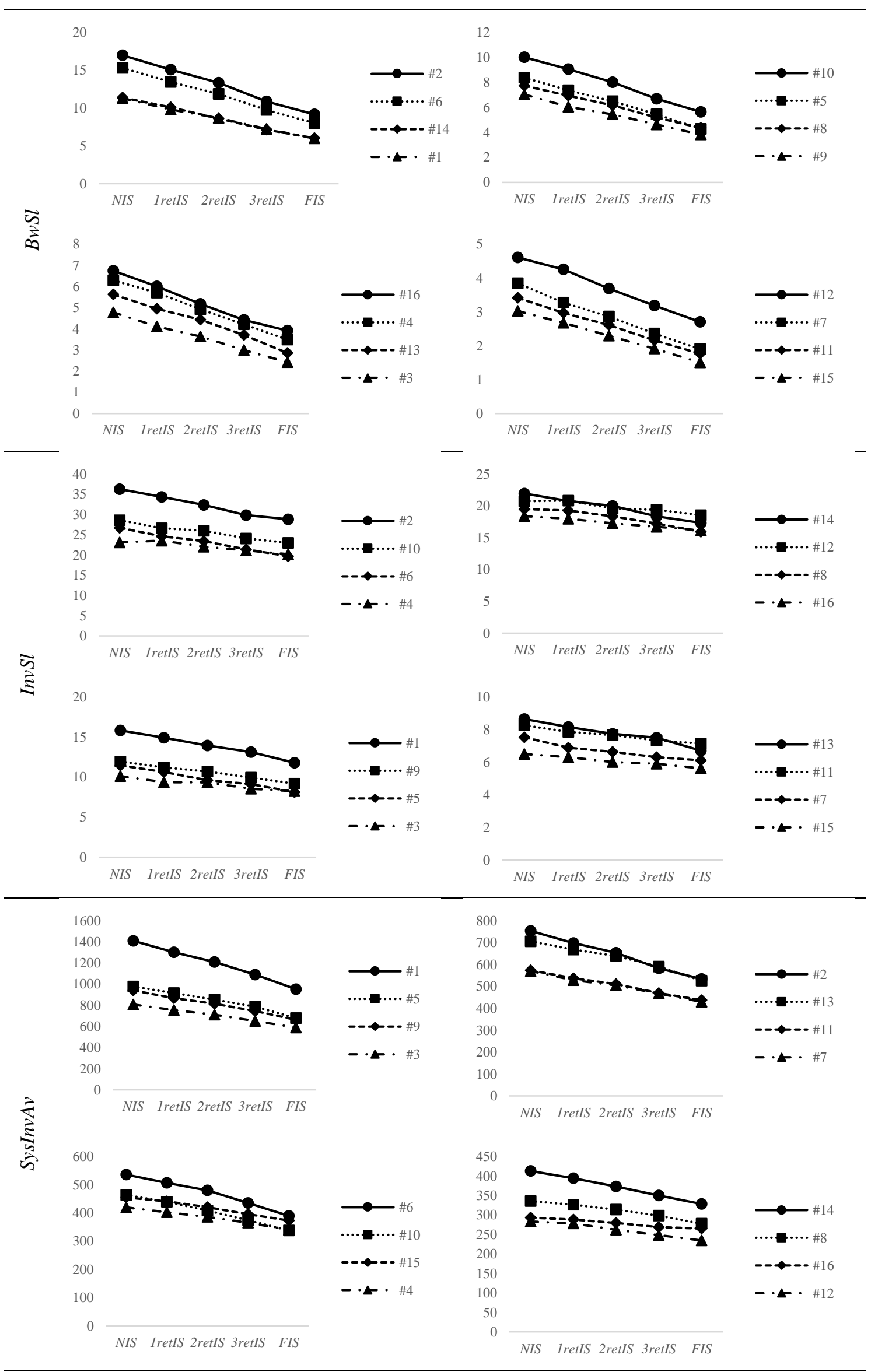

Figure 3. SC performance under the hypothesis of homogeneous retailers. 
Results show a quasi-linear performance improvement in $B w S l$ from NIS to FIS, with all curves yielding a coefficient of determination $\left(R^{2}\right)$ over 0.99 . In fact, since retailers are identical and transmit demand information, it is expected that the impact of IS on reducing demand variability would be linear with the number of retailers. However, curves related to the inventory metrics (InvSl and SysInvAv) are not strictly linear, with $67 \%$ of all curves yielding a coefficient of determination over $99 \%$, and the rest of the curves showing small deviations from linearity, with $0.90<R^{2}<0.99$. This result suggests that the impact of transmitting demand information on inventory performance improvement is linear with the number of retailers in most cases, but it may present some non-linearity.

Performance curves show different slopes depending on retailers' operational configurations. Thus, benefits of incorporating a retailer to IS may depend on current retailers' operational configuration. In order to appreciate this phenomenon, we compute the percentage of performance improvement for each metric from NIS to 2 retIS and from NIS to FIS for each of the 16 retailers' operational configurations and plot the results in Figure 4. A generic formulation of this measure is shown in Equation (15), where 'metric' can be either $B w S l$, InvSl or $S y \operatorname{Inv} A v$, and $A, B$ represent any of the IS structures.

$$
\Delta \operatorname{metric}_{A \rightarrow B}(\%)=\frac{\left(\text { metric }_{A}-\text { metric }_{B}\right)}{\text { metric }_{A}} * 100
$$

From Figure 4 it can be seen that the benefits obtained in terms of $B w S l$ reduction are less dependent on retailers' operational configuration than those related to InvSl and SysInvAv. In fact, performance improvement in terms of $B w S l$ is very similar for all scenarios. This result indicates that the expected bullwhip reduction from adding retailers to IS weakly depends on retailers' operation. Nevertheless, the performance improvement related to InvSl and SysInvAv show a stronger dependence on retailers' operational configuration. Additionally, BwSl reduction is higher than InvSl and SysInvAv reductions: there is an average $B w S l$ reduction of around $20 \%-25 \%$ for 2 retIS and around 40\%-50\% for FIS, while average InvSl and SysInvAv reductions are around $5 \%-16 \%$ for 2 retIS and $10 \%-32 \%$ for FIS.

We can summarize the above findings as follows: 
Dominguez R., Cannella S., Póvoa A.P., Framinan J.M. 2017. Information sharing in supply chains with heterogeneous retailers. Omega. DOI: https://doi.org/10.1016/j.omega.2017.08.005

(1) The improvement in BwSl in a SC with homogenous retailers obtained by information sharing is linear with the number of retailers sharing information. Nevertheless some (weak) non-linearity appears for InvSl and SysInvAv metrics.

(2) The improvement in BwSl in a SC with homogeneous retailers obtained by information sharing:

a. It is higher than for InvSl and SysInvAv metrics.

b. It is less dependent on retailers' operational configuration than for InvSl and SysInvAv metrics.
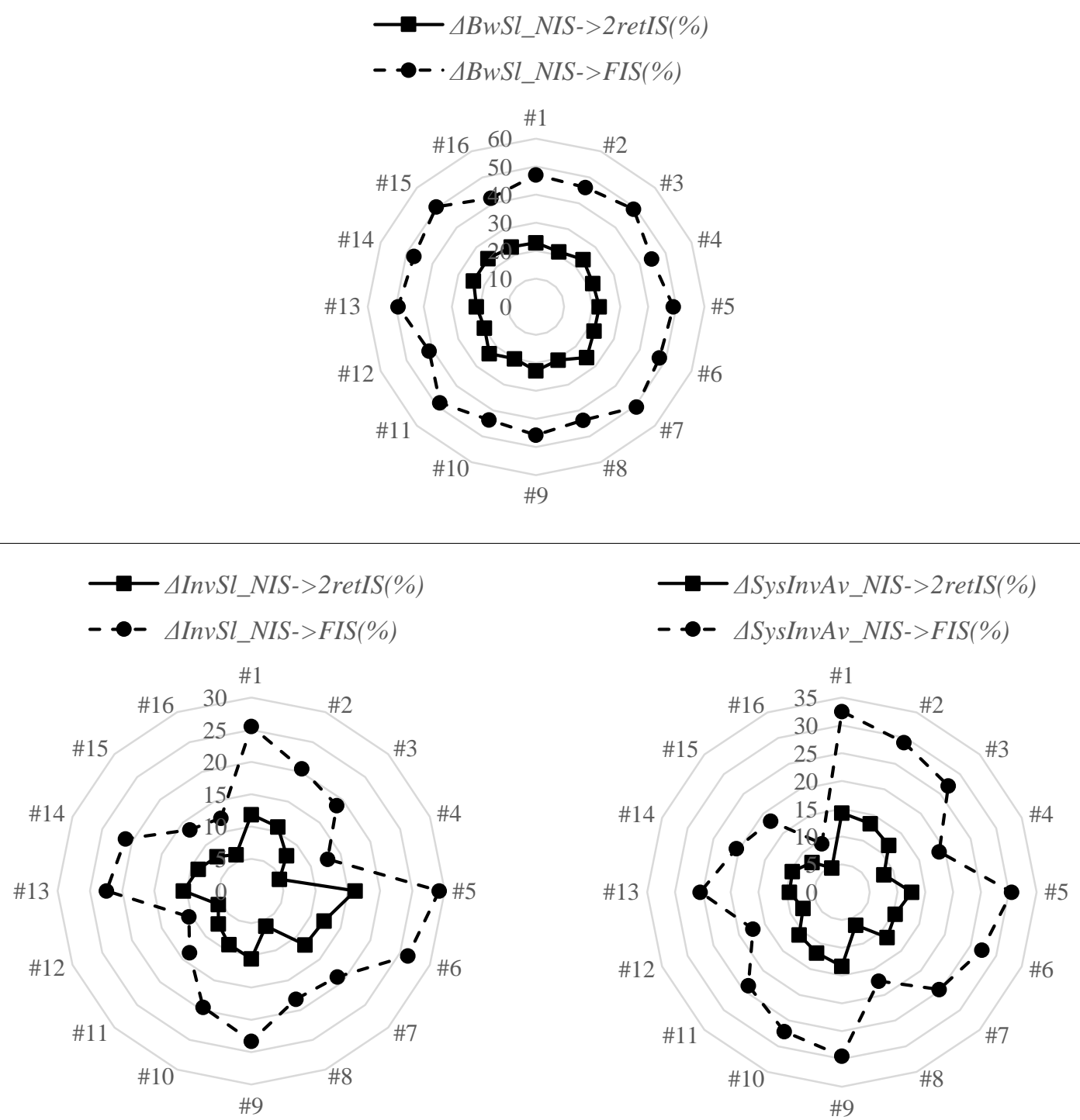

Figure 4. SC performance improvement for all the retailers' operational configurations. 


\subsection{Heterogeneous retailers}

Herein we present the results obtained under the hypothesis of heterogeneous retailers.

Due to the large amount of data obtained, we just present a sample case in Figure 5. More specifically, for each $\mathrm{OF}=\mathrm{OF}^{*}$, we select one of the 8 retailers' operational configurations (see DoE, Table 3) and present the results for the three metrics. For each metric, results obtained for NIS, OFLIS, OFHIS and FIS are averaged over the 20 replications. Since there are two intermediate possibilities to go from NIS to FIS (either through $O F L I S$ or $O F H I S)$, both curves are plotted in Figure 5.

As seen in Figure 5, the performance improvement obtained from the addition of new retailers to IS is not linear for all four OFs under consideration and for all metrics. In fact, the slopes of the curves depend on which retailers are sharing information (either in the OFLIS or in the OFHIS structure). As a consequence, for any given $\mathrm{OF}=\mathrm{OF}^{*}$ it can be observed a performance gap between the OFLIS and the OFHIS structures, so it can be concluded that the performance improvement structure depends on retailers' operational configuration.

In order to assess how OFs impact the observed performance gaps between OFLIS and OFHIS, we consider the results obtained from the full set of experiments (allowing for the 8 different retailers' operational configurations for each $\mathrm{OF}=\mathrm{OF}^{*}$ ). Numerical results are shown in Table 5 (results are averaged across the 20 simulations). The first row shows a range of performance improvement values in percentage that can be achieved under a FIS structure for each metric $\left(\operatorname{smetric}_{N I S \rightarrow F I S}(\%)\right)$. It can be noticed that these values are similar to those obtained assuming homogeneous retailers. Then, for each metric, a given column of Table 5 shows the results obtained for the 8 retailers' operational configurations (labelled from \#1 to \#8) when the OF indicated in the second row is the $\mathrm{OF}^{*}$. For each retailer operational configuration, the absolute values for OFLIS and OFHIS are provided (values for NIS and FIS are omitted to make the results clearer).

We use ANOVA to statistically assess the significance of the performance gaps observed between OFLIS and OFHIS (see Table 5, where scenarios with non-significant performance gap with a $95 \%$ confidence level are shaded in grey). These results indicate that, when retailers with different operational configurations are involved in IS, 
Dominguez R., Cannella S., Póvoa A.P., Framinan J.M. 2017. Information sharing in supply chains with heterogeneous retailers. Omega. DOI: https://doi.org/10.1016/j.omega.2017.08.005

performance gaps have a high probability to occur for any of the three proposed metrics, i.e., BwSl (96.88\%), InvSl (87.50\%) and SysInvAv (90.63\%).

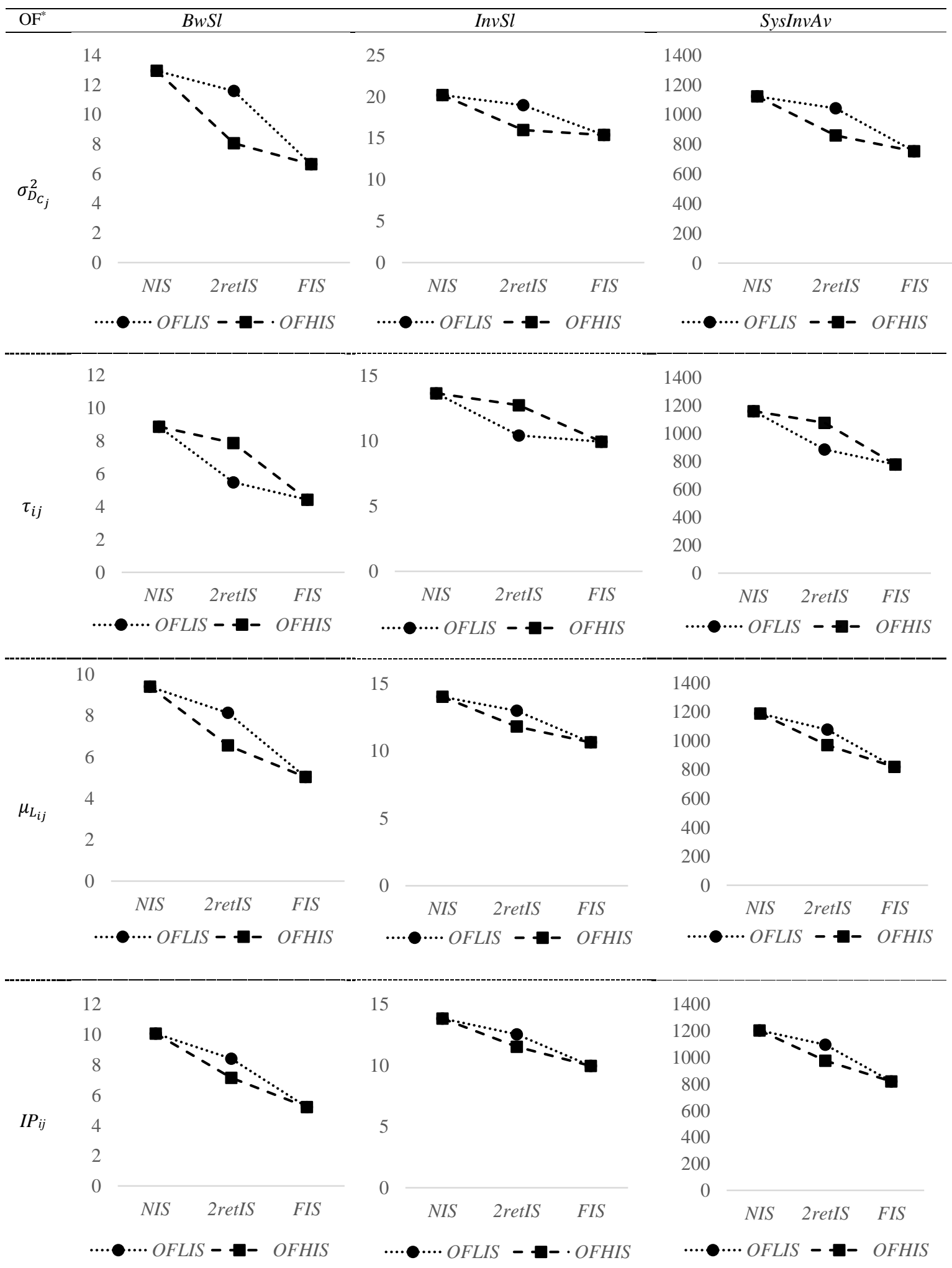

Figure 5. A sample of SC performance under the hypothesis of heterogeneous retailers. 
Dominguez R., Cannella S., Póvoa A.P., Framinan J.M. 2017. Information sharing in supply chains with heterogeneous retailers. Omega. DOI: https://doi.org/10.1016/j.omega.2017.08.005

Table 5. Numeric results for heterogeneous retailers.

\begin{tabular}{|c|c|c|c|c|c|c|c|c|c|c|c|c|c|}
\hline & \multirow{3}{*}{$\begin{array}{r}\Delta \text { metric }(\%) \\
\text { NIS } \rightarrow \text { FIS } \\
\text { OF* }^{*}\end{array}$} & \multicolumn{4}{|c|}{$B w S l$} & \multicolumn{4}{|c|}{$\operatorname{InvSl}$} & \multicolumn{4}{|c|}{ SysInvAv } \\
\hline & & \multicolumn{4}{|c|}{$[41,41-51,56]$} & \multicolumn{4}{|c|}{$[10,22-28,21]$} & \multicolumn{4}{|c|}{$[14,57-32,94]$} \\
\hline & & $\sigma_{D_{C_{j}}}^{2}$ & $I P_{i j}$ & $\mu_{L_{i j}}$ & $\tau_{i j}$ & $\sigma_{D_{C_{j}}}^{2}$ & $I P_{i j}$ & $\mu_{L_{i j}}$ & $\tau_{i j}$ & $\sigma_{D_{C_{j}}}^{2}$ & $I P_{i j}$ & $\mu_{L_{i j}}$ & $\tau_{i j}$ \\
\hline & OFLIS & 11,58 & $\delta$ & & 5,47 & ,97 & 12,55 & 12,96 & 10,43 & 1041,66 & 1096,65 & 1076,97 & לנים \\
\hline & OFHIS & 8,05 & 7,15 & 6,55 & 7,86 & 15,98 & 11,52 & 11,79 & 12,76 & 859,59 & 975,78 & 968,94 & 1077,23 \\
\hline & Ametric $(\%)$ & 30,47 & 14,99 & 19,44 & $-30,41$ & 15,79 & 8,17 & 9,04 & $-18,21$ & 17,48 & 11,02 & 10,03 & $-17,72$ \\
\hline & OFLIS & 4,57 & 11,76 & 10,56 & 7,31 & 13,05 & 28,92 & 0,25 & 25 & 列 & , & 94 & 年 \\
\hline & OFHIS & 3,16 & 12,57 & 9,49 & 9,58 & 11,15 & 29,38 & 28,20 & 28,93 & 508,01 & 546,17 & 500,10 & 538,07 \\
\hline & Ametric $(\%)$ & 30,87 & $-6,90$ & 10,13 & $-23,76$ & 14,58 & $-1,57$ & 6,77 & $-10,46$ & 14,04 & 4,58 & 7,38 & $-13,20$ \\
\hline & OFLIS & 9,10 & 3,47 & 3,40 & 3,99 & 13,67 & 8,05 & 8,63 & 7,59 & 746,25 & 631,4 & 631,36 & 623,3 \\
\hline & OFHIS & 6,29 & 3,12 & 2,88 & 5,77 & 11,20 & 7,94 & 8,2 & , & 614,27 & 584,93 & 581,28 & 100 \\
\hline & $\Delta m e t r i c(\%)$ & 30,83 & 10,09 & 15,13 & $-30,90$ & 17,54 & 1,39 & 4,98 & $-21,12$ & 17,69 & 7,37 & 7,93 & $-17,54$ \\
\hline & OFLIS & 3,83 & דו & 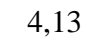 & , & 6 & 2 & 2, & 19 & 422,46 & & 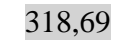 & 8 \\
\hline & OFHIS & 2,92 & 5,66 & 3,99 & 9,49 & 8,21 & 22,00 & 20,73 & 22,00 & 372,88 & 341,74 & 314,07 & 411,64 \\
\hline & Ametric(\%) & 23,62 & $-15,27$ & 3,30 & $-20,35$ & 11,34 & $-6,71$ & 1,34 & $-11,75$ & 11,74 & $-3,20$ & 1,45 & $-11,50$ \\
\hline \multirow{3}{*}{ \# } & OFLIS & 94 & 5,16 & 6,1 & 3,65 & 14,76 & 9,30 & 9,58 & 8,56 & 673,85 & 746,76 & 43 & 620,8 \\
\hline & OFHIS & 90 & 4,93 & 5,17 & 4,77 & 12,58 & 8,94 & 8,37 & 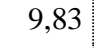 & 563,69 & 698,95 & 718,39 & 707,02 \\
\hline & Ametric(\%) & 29,38 & 4,30 & 16,40 & $-23,52$ & 14,76 & 3,80 & 12,66 & $-12,93$ & 16,35 & 6,40 & 10,02 & $-12,19$ \\
\hline & 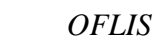 & 2 & 7,35 & 1 & 8 & 68 & 65 & 4 & 2 & J & J & Y & 09 \\
\hline & OFHIS & 2,23 & 8,65 & 9,47 & 5,74 & 9,74 & 23,86 & 20,73 & 23,16 & 355,44 & 380,50 & 400,15 & 332,79 \\
\hline & Ametric(\%) & 30,81 & $-17,8$ & 2 & -14 & 8,78 & $-5,3$ & 4,61 & -3 , & 6 & -( & 89 & $-7,54$ \\
\hline \multirow{3}{*}{ \# } & OFLIS & 6,10 & 2,49 & 2 & 2,93 & 10,94 & 6,84 & 6,52 & 6 & 4 & 460 & 73 & 4962 \\
\hline & OFHIS & F & 2,36 & 2,40 & 3,87 & 3 & 0,04 & 6,20 & 7,66 & 466,26 & 44 & 448,80 & 00 \\
\hline & Ametric $(\%)$ & 26,35 & 5,05 & 9,10 & $-24,20$ & 15,62 & $-0,09$ & 4,88 & $-14,30$ & 15,26 & 4,65 & 4,86 & $-12,28$ \\
\hline \multirow{3}{*}{ \#8 } & OFLIS & 3,09 & 3,91 & 5,36 & 0,08 & 61 & 18,59 & 17,55 & 17,30 & 355,60 & 256,54 & 288,57 & 307,81 \\
\hline & OFHIS & 2,49 & 4,62 & 5,28 & 7,04 & 8,13 & 19,79 & 17,52 & 19,14 & 324,54 & 26 & 282,80 & 327,88 \\
\hline & Ametric(\%) & 19,50 & $-18,32$ & 1,46 & $-13,65$ & 5,62 & $-6,47$ & 0,17 & $-9,59$ & 8,73 & $-1,88$ & 2,00 & $-6,12$ \\
\hline
\end{tabular}

We can summarize the above findings as follows:

(3) For heterogeneous retailers the performance improvement obtained by information sharing

a. Depends on retailers' operational configuration, and;

b. It is not linear with the number of retailers involved.

(4) For heterogeneous retailers the majority of the analysed scenarios show significant performance gaps between partial information sharing structures with identical number of retailers.

The existence of performance gaps among different partial IS structures creates the opportunity to achieve higher SC performance improvement with some specific 
structures (see Section 5 for a detailed discussion). Hence, we focus our analysis on the performance gaps. To do so, we measure the percentage of performance variation between OFLIS and OFHIS using OFLIS as reference, i.e., $\operatorname{metric}_{\text {OFLIS } \rightarrow \text { OFHIS }}(\%)$. Results are shown in Table 5 under the label $\Delta m e t r i c(\%)$.

For a given $\mathrm{OF}=\mathrm{OF}^{*}$, the sign of $\triangle m e t r i c(\%)$ indicates which IS structure (either OFLIS or OFHIS structure) provides the best performance. For $\mathrm{OF}^{*}=\sigma_{D_{C_{j}}}^{2}$ and $\mathrm{OF}^{*}=\mu_{L_{i j}}$ the sign of $\Delta m e t r i c(\%)$ is always positive, thus indicating that the OFHIS structure (i.e. involving retailers with higher value of $\sigma_{D_{C_{j}}}^{2}$ or $\mu_{L_{i j}}$ ) is more favourable. On the contrary, for $\mathrm{OF}^{*}=\tau_{i j}$ the sign of $\Delta m e t r i c(\%)$ is always negative, indicating that the OFLIS structure (i.e., involving retailers with lower value of $\tau_{i j}$ ) is more favourable. Finally, for $\mathrm{OF}^{*}=I P_{i j}$ there is not a dominant sign of $\Delta m e t r i c(\%)$, since it can be positive or negative depending on retailers' operational configuration. Therefore, it is not clear which level of $I P_{i j}$ is more favourable.

In order to assess how each $\mathrm{OF}=\mathrm{OF}^{*}$ may impact on $\Delta$ metric $(\%)$, we also compute related statistical data (i.e., average, standard deviation, and coefficient of variation (c.v.)) for each metric over the 8 retailers' operational configurations (see Table 6). The absolute average of $\Delta m e t r i c(\%)$ measures the overall performance gap found between OFLIS and OFHIS for a given $\mathrm{OF}=\mathrm{OF}^{*}$, indicating the relevance of such factor on producing a significant gap. The relative variability (c.v.) of $\Delta$ metric(\%) measures how reliable is the obtained average (or how the obtained performance gaps depends on retailers' operational configuration). Using these statistics we can infer on which OFs are more decisive to create performance gaps.

From the results, it can be seen that $\mathrm{OF}^{*}=\sigma_{D_{C_{j}}}^{2}$ and $\mathrm{OF}^{*}=\tau_{i j}$ provide the highest (absolute) average $\Delta m e t r i c(\%)$ for all the three metrics with a low dependence of retailers' operational configuration. The next factor in importance is $\mathrm{OF}^{*}=\mu_{L_{i j}}$, with lower average and higher dependence of retailers' operational configuration. Finally, $\mathrm{OF}^{*}=I P_{i j}$ obtains an average close to zero and very high c.v., thus indicating that performance gaps are highly dependent on retailers' operational configuration, and the value of $\Delta m e t r i c(\%)$ alternates between positive and negative. Also, it can be noticed that $\Delta m e t r i c(\%)$ obtained for $B w S l$ are more important than those obtained for InvSl or SysInvAv. 
Dominguez R., Cannella S., Póvoa A.P., Framinan J.M. 2017. Information sharing in supply chains with heterogeneous retailers. Omega. DOI: https://doi.org/10.1016/j.omega.2017.08.005

Table 6. Some statistics for the scenario with heterogeneous retailers.

\begin{tabular}{|c|c|c|c|c|c|}
\hline$\Delta m e t r i c(\%)$ & Statistics & $\mathrm{OF}^{*}=\sigma_{D_{C_{j}}}^{2}$ & $\mathrm{OF}^{*}=I P_{i j}$ & $\mathrm{OF}^{*}=\mu_{L_{i j}}$ & $\mathrm{OF}^{*}=\tau_{i j}$ \\
\hline \multirow{3}{*}{$\Delta B w S l_{O F L I S \rightarrow O F H I S}(\%)$} & Average & 27,73 & $-2,98$ & 10,27 & $-22,71$ \\
\hline & Standard Dev. & 4,24 & 13,27 & 6,35 & 6,32 \\
\hline & c.v. & 0,15 & 4,45 & 0,62 & 0,28 \\
\hline \multirow{3}{*}{$\Delta I n v S l_{O F L I S \rightarrow O F H I S}(\%)$} & Average & 13,00 & $-0,85$ & 5,56 & $-12,68$ \\
\hline & Standard Dev. & 4,07 & 5,28 & 4,01 & 5,50 \\
\hline & c.v. & 0,31 & 6,19 & 0,72 & 0,43 \\
\hline \multirow{3}{*}{$\Delta S y \operatorname{Inv} v_{\text {OFLIS } \rightarrow \text { OFHIS }}(\%)$} & Average & 14,28 & 3,54 & 6,57 & $-12,26$ \\
\hline & Standard Dev. & 3,07 & 4,97 & 3,42 & 4,12 \\
\hline & c.v. & 0,22 & 1,40 & 0,52 & 0,34 \\
\hline$\Delta B w S l_{O F L I S / F I S}(\%)$ & \multirow{2}{*}{ Average } & 24,88 & 54,06 & 43,37 & 71,71 \\
\hline$\Delta B w S l_{O F H I S / F I S}(\%)$ & & 74,24 & 49,64 & 61,14 & 31,94 \\
\hline$\Delta I n v S l_{O F L I S / F I S}(\%)$ & \multirow{2}{*}{ Average } & 21,94 & 54,48 & 38,74 & 77,60 \\
\hline$\Delta I n v S l_{O F H I S / F I S}(\%)$ & & 85,62 & 44,13 & 63,33 & 26,03 \\
\hline$\Delta S y s \operatorname{Inv} A v_{O F L I S / F I S}(\%)$ & \multirow{2}{*}{ Average } & 20,33 & 41,21 & 36,74 & 70,71 \\
\hline$\Delta S y s I n v A v_{O F H I S / F I S}(\%)$ & & 73,79 & 51,51 & 60,65 & 26,36 \\
\hline
\end{tabular}

We can summarize these findings as follow:

(5) For heterogeneous retailers the observed performance gaps between partial information sharing structures with identical number of retailers depends on the retailers' operational configuration.

(6) A rank of the operational factors of the retailers according to the significance and reliability of their impact on the observed performance gaps is as follows: (I) (higher) demand variance; (II) (lower) forecasting period; and (III) (higher) lead time average. It is not clear how the different configurations of the OUT policy contribute to the observed performance gaps.

(7) For heterogeneous retailers the performance improvement obtained by information sharing measured in terms of BwSl is higher and less dependent on retailers' operational configuration than those obtained for InvSl and SysInvAv.

An interesting perspective can be given by observing the percentage of performance improvement obtained by a certain partial IS structure (either OFLIS or OFHIS) related to the performance improvement obtained by a FIS structure (Equations (16) and (17)).

$$
\begin{aligned}
& \operatorname{metric}_{O F L I S / F I S}(\%)=\frac{\left(\text { metric }_{N I S}-\text { metric }_{O F L I S}\right)}{\left(\text { metric }_{N I S}-\text { metric }_{F I S}\right)} * 100 \\
& \Delta \text { metric }_{O F H I S / F I S}(\%)=\frac{\left(\text { metric }_{N I S}-\text { metric }_{O F H I S}\right)}{\left(\text { metric }_{N I S}-\text { metric }_{F I S}\right)} * 100
\end{aligned}
$$


Values are shown in Table 6. We found significant differences between both IS structures for some OFs. This means that a substantial part of the benefits obtained by a FIS structure can be achieved by choosing one of the partial IS structures. Particularly it can be seen involving $50 \%$ of the total number of retailers into IS yields around $70 \%$ of the average performance improvement of a FIS for $\mathrm{OF}^{*}=\sigma_{D_{C_{j}}}^{2}$ and $\mathrm{OF}^{*}=\tau_{i j}$, and around $60 \%$ of a $F I S$ for $\mathrm{OF}^{*}=\mu_{L_{i j}}$, for all retailers' configurations and all the three metrics. On the contrary, choosing the alternative partial IS structure may lead to obtain a poor performance increase, as it can be seen in Table 6. Average values obtained for $\mathrm{OF}^{*}=$ $I P_{i j}$ are close to $50 \%$ for the reasons discussed above. Also, it can be noticed that these values are slightly higher for InvSl than for BwSl and SysInvAv.

We formalize this last finding as follows:

(8) A partial information sharing structure implemented according to the recommendations of finding (6) is able to achieve a significant part of the benefits provided by full information sharing. On the contrary, alternative partial information sharing structures may lead to a poor performance increase when compared to a full information sharing structure.

The above findings can be better appreciated using plots. As an example, the results obtained for $B w S l$ are shown in Figure 6. The performance increase for partial IS structures $\quad\left(\Delta B w S l_{N I S \rightarrow O F L I S}(\%)\right.$ and $\left.\Delta B w S l_{N I S \rightarrow O F H I S}(\%)\right)$ and FIS $\left(\Delta B w S l_{N I S \rightarrow F I S}(\%)\right)$ is shown in different plots for each $\mathrm{OF}=\mathrm{OF}^{*}$ and for the 8 retailers' operational configurations. Also, as reference, the 50\% FIS line is also represented.

The area encircled between curves of partial IS structures is representative of the performance gaps obtained over the considered retailers' operational configurations: the higher the area between the curves, the higher the average performance gap obtained; the higher the parallelism between curves, the less dependence from retailers' operational configuration. It can be seen that, in fact, the best results are found for $\mathrm{OF}^{*}=\sigma_{D_{C_{j}}}^{2}$ and $\mathrm{OF}^{*}=\tau_{i j}$, with significant performance gaps and low dependence of retailers' operational configuration. Furthermore, it can be seen how a partial IS structure is able to achieve a performance improvement that is clearly over the $50 \%$ of FIS. For $\mathrm{OF}^{*}=\mu_{L_{i j}}$, the performance gaps are lower and the results show a higher dependence of retailers' operational configuration, but still is possible to achieve a good 
performance improvement by partial IS. In the case of $\mathrm{OF}^{*}=I P_{i j}$ it can be seen that the results are highly dependent on retailers' operational configuration and it is not clear which retailers are more favourable.

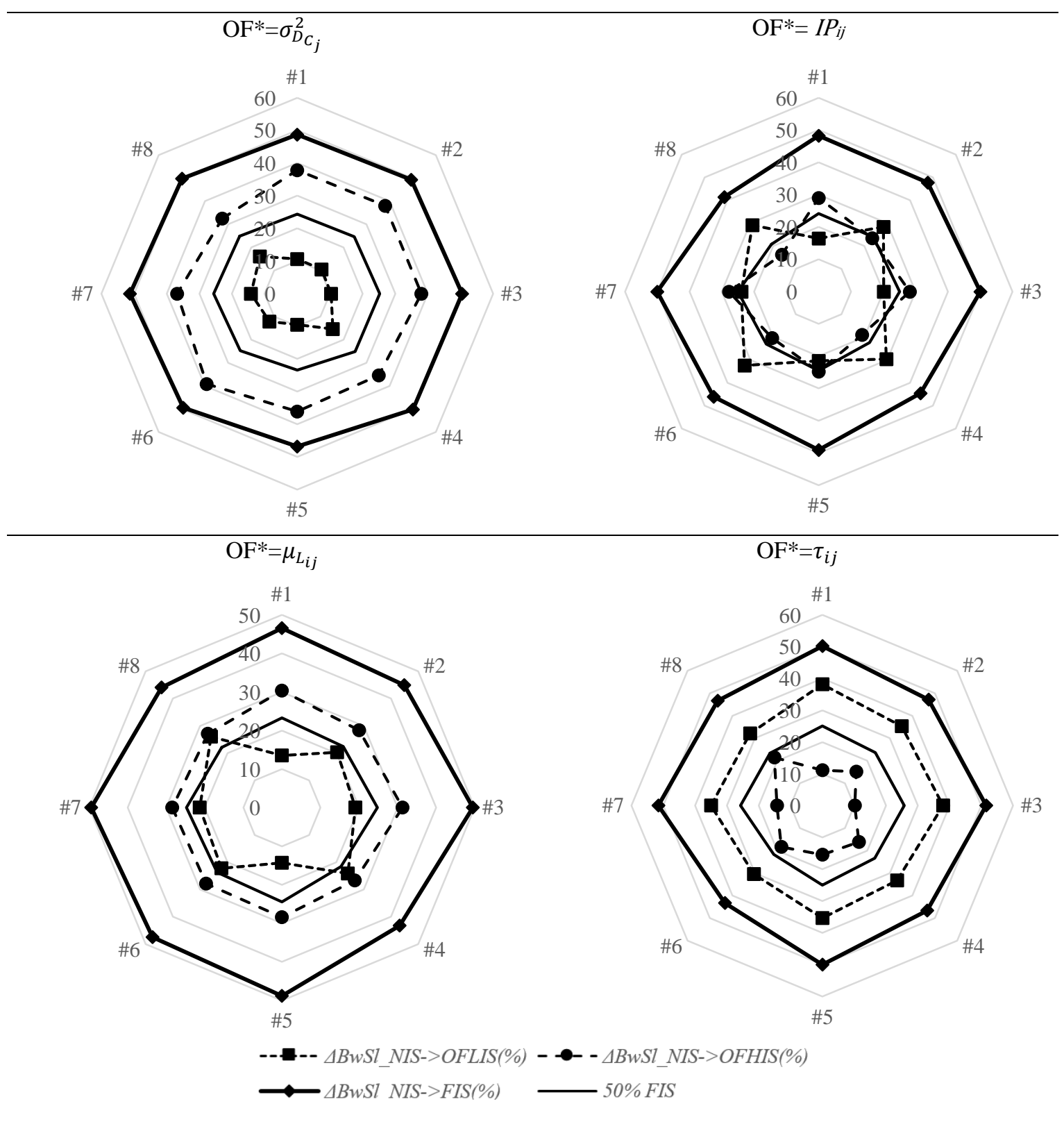

Figure 6. SC performance increase $(B w S l)$ under partial IS and FIS for heterogeneous retailers.

\subsubsection{Sensitivity analysis on retailers'demand variance and forecasting period}

In order to enhance the simulation models and to extend the applicability of the results obtained, we perform a sensitivity analysis (Kleijnen 2008) with respect to the more relevant $\mathrm{OFs}$ (i.e., $\mathrm{OF}^{*}=\sigma_{D_{C_{j}}}^{2}$ and $\mathrm{OF}^{*}=\tau_{i j}$ ). Since the values assumed by the OFs in 
Table 2 are different in order to ensure a heterogeneous scenario, in this further analysis we aim to address the following question: how much the results will change if the differences between retailers' OFs are reduced? To do so, we analyse (1) two new variants for demand variance, with the $O F H$ value reduced to $\dot{\sigma}_{D_{C_{j}}}=17.5\left(\dot{\sigma}_{D_{C_{j}}}^{2}=306.25\right)$ in the first variant and to $\ddot{\sigma}_{D_{C_{j}}}=15\left(\ddot{\sigma}_{D_{C_{j}}}^{2}=225\right)$ in the second variant; and (2) two new variants for the forecasting period, with the $O F L$ value increased to $\dot{\tau}_{i j}=7$ in the first variant and to $\ddot{\tau}_{i j}=9$ in the second variant. For each new variant we analyse the full factorial combination of the $\mathrm{OF} \neq \mathrm{OF}^{*}$, which maintains the original values, as in Table 7. Therefore we analyse a total of 4 (variants) $\times 8$ (full factorial $\mathrm{OF} \neq \mathrm{OF}^{*}$ ) $\times 4$ (IS structures $)=128$ SCs (2560 simulation runs).

Following the same procedure carried out in Section 4.2, we compute Equations (16) and (17) and show the average values for each metric in Table 8. As it could be expected, the advantages or disadvantages obtained from OFLIS or OFHIS structures (i.e., differences between $\Delta$ metric $_{O F L I S / F I S}(\%)$ and $\Delta$ metric $_{O F H I S / F I S}(\%)$ ) are lower as the differences between OFs decrease.

Table 7. DoE for the sensitivity analysis on ${\sigma_{D_{C_{j}}}^{2}}^{2}$ and $\tau_{i j}$.

\begin{tabular}{|c|c|c|c|c|c|c|c|c|}
\hline \multirow{3}{*}{ OFs } & \multicolumn{4}{|c|}{$\sigma_{D_{C_{j}}}^{2}$ sensitivity } & \multicolumn{4}{|c|}{$\tau_{i j}$ sensitivity } \\
\hline & \multicolumn{2}{|c|}{$1^{\text {st }}$ variant } & \multicolumn{2}{|c|}{$2^{\text {nd }}$ variant } & \multicolumn{2}{|c|}{$1^{\text {st }}$ variant } & \multicolumn{2}{|c|}{$2^{\text {nd }}$ variant } \\
\hline & $O \dot{F} L$ & $O \dot{F} H$ & $O \ddot{F} L$ & $O \ddot{F} H$ & $O \dot{F} L$ & $O \dot{F} H$ & $O \ddot{F} L$ & $O \ddot{F} H$ \\
\hline$\sigma_{D_{C_{j}}}^{2}$ & 100 & 306.25 & 100 & 225 & 100 & 400 & 100 & 400 \\
\hline$\tau_{i j}$ & 5 & 15 & 5 & 15 & 7 & 15 & 9 & 15 \\
\hline$\mu_{L_{i j}}$ & 2 & 4 & 2 & 4 & 2 & 4 & 2 & 4 \\
\hline$I P_{i j}$ & $S 1$ & $S 2$ & $S 1$ & $S 2$ & $S 1$ & $S 2$ & $S 1$ & $S 2$ \\
\hline
\end{tabular}

For $\mathrm{OF}^{*}=\sigma_{D_{C_{j}}}^{2}$, differences between $\Delta$ metric $_{\text {OFLIS } / F I S}(\%)$ and $\Delta$ metric $_{\text {OFHIS/FIS }}(\%)$ smoothly decrease as the $O F H$ value decreases. In the first variant, where the c.v. of the demand faced by $O F H$ retailers changes from 0.4 to 0.35 and the c.v. of demand faced by $O F L$ retailers remains the same (i.e., c.v. $=0.2$ ), the benefits obtained from $O F H I S$ still represent over $70 \%$ of the benefits of a FIS for the three metrics. In the second 
variant, where the c.v. of the demand faced by $O F H$ retailers is reduced to 0.30 , benefits obtained from OFHIS are still significantly higher than benefits obtained from OFLIS.

For $\mathrm{OF}^{*}=\tau_{i j}$, the difference between $\Delta$ metric $_{O F L I S / F I S}(\%)$ and $\Delta$ metric $_{O F H I S / F I S}(\%)$ decreases as the $O F L$ value increases. It is known that a high value of $\tau_{i j}$ produces a more stable forecast, while a low value of $\tau_{i j}$ produces a more nervous forecast. Therefore, as $\tau_{i j}$ increases for the $O F L$ retailers, forecast patterns of both pairs of retailers become more aligned, and the advantages obtained by choosing the OFLIS structure are consequently reduced.

Table 8. Results of the sensitivity analysis.

\begin{tabular}{|c|c|c|c|c|c|c|}
\hline & $\mathrm{OF}^{*}=\sigma_{D_{C_{j}}}^{2}$ & $\mathrm{OF}^{*}=\dot{\sigma}_{D_{C_{j}}}^{2}$ & $\mathrm{OF}^{*}=\ddot{\sigma}_{D_{C_{j}}}^{2}$ & $\mathrm{OF}^{*}=\tau_{i j}$ & $\mathrm{OF}^{*}=\dot{\tau}_{i j}$ & $\mathrm{OF}^{*}=\ddot{\tau}_{i j}$ \\
\hline$\Delta B w S l_{O F L I S / F I S}(\%)$ & 24,88 & 31,02 & 37,88 & 71,71 & 65,47 & 58,26 \\
\hline$\Delta B w S l_{O F H I S / F I S}(\%)$ & 74,24 & 71,18 & 65,40 & 31,94 & 38,80 & 49,75 \\
\hline$\Delta I n v S l_{O F L I S / F I S}(\%)$ & 21,94 & 24,92 & 29,75 & 77,60 & 74,91 & 66,81 \\
\hline$\Delta I n v S l_{O F H I S / F I S}(\%)$ & 85,62 & 71,46 & 56,20 & 26,03 & 30,53 & 46,56 \\
\hline$\Delta S y \operatorname{Inv} A v_{O F L I S / F I S}(\%)$ & 20,33 & 27,91 & 35,35 & 70,71 & 63,79 & 55,06 \\
\hline$\Delta S y \operatorname{sinv} A v_{O F H I S / F I S}(\%)$ & 73,79 & 72,33 & 65,31 & 26,36 & 35,45 & 45,85 \\
\hline
\end{tabular}

\section{DISCUSSION AND MANAGERIAL INSIGHTS}

In this section we discuss the managerial implications derived from our work. We focus on how SC mangers may successfully implement IS at retailers' stage, since it reports higher benefits to the SC (Lau et al. 2004, Ganesh et al. 2014a, Costantino et al. 2014). In this way we provide practical insights for the estimation of the potential value of each retailer (i.e., estimating the potential contribution of each retailer if they join IS to improve SC performance).

There are two possible approaches when implementing IS: a FIS approach, or a partial IS approach. The former always results in a higher improvement of SC performance than the latter, as we have seen in Section 4. However, implementing IS in a SC costs time (negotiations and physical installation of IT) and cash (IT is expensive), and retailers may ask for a large discount to share their information (Huang and Iravani 2005). Therefore, in terms of the net benefits our work highlights the need to consider 
retailers' operational characteristics in order to decide on which type of IS could be adopted.

If retailers are similar in terms of variance of customer demand, inventory policy, forecasting period and lead time average, the potential value of all of them is also similar when they are involved in IS. Therefore, a FIS approach should be pursued, since benefits increase with the number of retailers involved. Additionally, since all retailers have similar potential value, managers may start negotiations with those that are more prone to collaborate.

In case that a retailer, or group of retailers, significantly differs from the others in one or more of the aforementioned OFs, the benefits achieved by partial IS may significantly depend on the participant retailer/s. As shown in Section 4, a partial IS structure is able to achieve a significant part of the total benefits obtained by FIS if retailers are significantly different (e.g., we found that involving half of the total number of retailers into IS may lead to obtain over $70 \%$ of the total benefits of a FIS under the boundary conditions). Assuming a linear increase of costs with the number of retailers involved in IS, a cost-benefit analysis may reveal that a partial IS approach is more beneficial for the SC than a FIS approach, thus saving costs related to the involvement of additional retailers. On the other hand, an erroneous choice of the partial IS structure may result in a very low performance increase, undermining all efforts and investments. Consequently, a prior evaluation of the potential value of retailers may help managers to efficiently select a partial IS structure, constituted by the most beneficial retailers. To do so, retailers should be evaluated in this order of importance: (1) (higher) demand variance; (2) (lower) forecasting period; (3) (higher) average lead times. Naturally, these results are less significant as the differences between retailers' OFs decrease.

Once the partial IS structure to be adopted has been decided, managers may start implementing IS according to retailers' potential value. By doing so, the benefits obtained by each new retailer involved in IS are maximal and thus an efficient implementation of IS can be achieved.

Even though it has been shown that considering retailers' operation during the implementation of partial IS may provide important benefits for the SC, obtaining such information may present some difficulties. Only the lead time average of each retailer could be accessed (through the wholesaler). However, results obtained in this paper 
show that retailers' demand variance and retailers' forecasting period are the most significant OFs. Since these factors are retailers' private information, a precollaboration strategy to share these data needs to be developed with retailers prior to the implementation of partial IS. In this case, SC managers should start by developing channels of trust and/or revenue contracts.

To sum up, we suggest managers to implement partial IS at heterogeneous retailers using the following steps:

1. Analyse retailers' operational characteristics.

2. If they are significantly different in one or more OFs, estimate the potential value of each retailers' collaboration in IS and rank them accordingly.

3. Estimate costs of involving retailers into IS and perform a cost/benefit analysis.

4. Decide the best IS structure using results from 3) and proceed involving retailers according to 2 ).

\section{CONCLUSIONS AND FUTURE RESEARCH}

This work presents an exploratory study on partial information sharing at retailers level, i.e., some retailers may not participate in information sharing. We analyse the potential contribution of the participation of each individual retailer in information sharing under two different hypothesis: (1) retailers are homogeneous (i.e., they have identical operational configuration), and (2) retailers are heterogeneous (i.e., they have different operational configuration). Using a Multi-Agent Systems simulation approach, we model a four echelon supply chain with four retailers, with stochastic demands and lead times, using two common Order-Up-To inventory policies. Retailers' operation is characterized by four operational factors: demand variance, forecasting period, lead time average, and inventory policy. We measure the supply chain performance using systemic supply chain metrics: Bullwhip Slope, Inventory Slope and Systemic Inventory Average. Supply chain performance is measured for different partial information sharing structures and different retailers' operational configurations.

The results of our study emphasize the need of individually estimating the potential value of retailers' information prior to the implementation of information sharing, and provides the following insights: 
- When retailers are homogeneous they have equal potential value if they are involved in information sharing (i.e., they identically contribute to improve supply chain performance). Thus, a full information sharing approach is recommended.

- When retailers are heterogeneous they have different potential value if they are involved in information sharing, depending on their operational configuration.

As a consequence

○ The performance improvement achieved by different partial information sharing structures with the same number of retailers might be significantly different.

- A partial information sharing structure involving retailers with high potential value may capture a substantial part of the benefits of full information sharing.

- Assuming a linear increase of costs with the number of retailers involved in information sharing, a cost-benefit analysis may reveal that a partial information sharing approach is more beneficial for the supply chain than a full information sharing approach, thus saving costs related to the involvement of additional retailers.

- Retailers' operation need to be carefully examined in order to develop an efficient implementation of information sharing. In this order of importance, retailers with (1) higher demand variance, (2) lower forecasting period, and (3) higher average lead time, are potentially more beneficial partners for implementing information sharing.

Due to the complex relationships between retailers' operational factors and retailers' potential value when become participants of information sharing, it was not possible to come up with a single and precise rule for identifying the most beneficial information sharing structure. In fact, properly balancing each operational factor is still an issue. Nevertheless, the findings reported in this paper should help managers to better understand the opportunities for partial information sharing and put them in a stronger position in their negotiations about establishing information sharing links.

The present study has some limitations that may create room for improvement and further research. Also, due to the exploratory nature of this work, there are many ways of possible extensions: 
- Deepening the analysis of each operational factor by increasing the number of intermediate values, and considering other different set ups of supply chain (i.e., different demand or lead time distributions, different forecast methods, etc.) would provide additional results that might be useful to precisely balance the importance of each operational factor on a wide variety of conditions and to look for a single rule for choosing the best information sharing structure.

- Analysing scenarios where retailers may differ in more than one factor at the same time would provide more realistic results.

- This work analyses either homogeneous or heterogeneous retailers. The "grey zone" that falls in the middle of both scenarios has been briefly analysed through a sensitivity analysis. Determining the limits between both scenarios would be a significant contribution in this line of research.

- A similar analysis to that conducted in this work on other operational factors (e.g. lead time variance, forecast method, safety factor, etc.) would provide a wider perspective of this problem to supply chain managers.

- Results of this work are scalable to higher or lower number of retailers. However, it could be interesting to analyse how the upstream part of the supply chain may impact on the results obtained. More specifically, it should be addressed how the upstream supply chain structure and upstream member's operational configuration may impact on the implementation of information sharing at retailers. Additionally, a similar research to that presented in this work could be performed on the upstream echelons of the supply chain, in order to come up with a more general overview on how to efficiently implement information sharing in supply chain.

\section{ACKNOWLEDGEMENTS}

This research was supported by the Portuguese Foundation for Science and Technology [Grant SFRH/BPD/108491/2015], by the Italian Ministry of Education, University and Research (Rita Levi Montalcini fellow), and by the Spanish Ministry of Science and Innovation, under the project PROMISE with reference DPI201680750P. 
Dominguez R., Cannella S., Póvoa A.P., Framinan J.M. 2017. Information sharing in supply chains with heterogeneous retailers. Omega. DOI: https://doi.org/10.1016/j.omega.2017.08.005

\section{REFERENCES}

Agrawal, S., Sengupta, R.N., Shanker, K. 2009. Impact of information sharing and lead time on bullwhip effect and on-hand inventory. European Journal of Operational Research, 192(2), 576-593.

Ali, M. M., Babai, M. Z., Boylan, J. E., Syntetos, A. A. 2017. Supply chain forecasting when information is not shared. European Journal of Operational Research, 260(3), 984-994.

Altomonte, C., Mauro, F. D., Ottaviano, G., Rungi, A., Vicard, V. 2012 Global value chains during the great trade collapse: a bullwhip effect?. European Central Bank. Working Paper Series 1412.

Annarelli, A., Nonino, F. 2016. Strategic and operational management of organizational resilience: Current state of research and future directions. Omega, 62, 1-18.

Bian, W., Shang, J., Zhang, J. 2016. Two-way information sharing under supply chain competition. International Journal of Production Economics, 178, 82-94.

Bischak, D.P., Robb, D.J., Silver, E.A., Blackburn, J.D. 2014. Analysis and management of periodic review, Order-Up-To level inventory systems with order crossover. Production and Operations Management, 23 (5), 762-772.

Cachon, G.P., Olivares, M. 2010. Drivers of finished-goods inventory in the U.S. automobile industry. Management Science, 56 (1), 202-216.

Cannella, S., Barbosa-Povoa, A.P., Framinan J.M., Relvas S. 2013. Metrics for bullwhip effect analysis. Journal of the Operational Research Society, 64, 1-16.

Cannella, S., Ciancimino, E. 2010. On the bullwhip avoidance phase: supply chain collaboration and order smoothing. International Journal of Production Research, 48 (22), 6739-6776.

Cannella, S., Dominguez, R., Framinan, J.M. 2017. Inventory record inaccuracy - The impact of structural complexity and lead time variability. Omega, 68, 123-138.

Cannella, S., López-Campos, M., Dominguez, R., Ashayeri, J., Miranda, P.A. 2015. A simulation model of a coordinated decentralized supply chain. International Transactions in Operational Research, 22 (4), 735-756.

Cardoso, S.R., Barbosa-Póvoa, A.P., Relvas, S., Novais, A.Q. 2015. Resilience metrics in the assessment of complex supply-chains performance operating under demand uncertainty. Omega, 56, 53-73.

Chan, H.K., Chan, F.T.S. 2010. A Review of Coordination Studies in the Context of Supply Chain Dynamics. International Journal of Production Research, 48 (10), 2793-2819.

Chase, R. B., Jacobs, F. R., Aquilano, N. J. 2004. Operations management for competitive advantage (10th ed.). Boston, MA: Irwin/McGraw-Hill.

Chatfield, D. C., Harrison, T. P., Hayya, J. C. 2006. SISCO: An object-oriented supply chain simulation system. Decision Support Systems, 42(1), 422-434.

Chatfield, D.C. 2013. Underestimating the bullwhip effect: A simulation study of the decomposability assumption. International Journal of Production Research, 51 (1), 230-244. 
Dominguez R., Cannella S., Póvoa A.P., Framinan J.M. 2017. Information sharing in supply chains with heterogeneous retailers. Omega. DOI: https://doi.org/10.1016/j.omega.2017.08.005

Chatfield, D.C., Hayya, J.C., Cook, D.P. 2013. Stockout propagation and amplification in supply chain inventory systems. International Journal of Production Research, 51 (5), 1491-1507.

Chatfield, D.C., Kim, J.G., Harrison, T.P., Hayya, J.C. 2004. The bullwhip effect - Impact of stochastic lead time, information quality, and information sharing: A simulation study. Production and Operations Management, 13 (4), 340-353.

Chatfield, D.C., Pritchard, A.M. 2013. Returns and the bullwhip effect. Transportation Research Part E: Logistics and Transportation Review, 49 (1), 159-175.

Chen, F., Drezner, Z., Ryan, J.K., Simchi-Levi, D. 2000. Quantifying the bullwhip effect in a simple supply chain: The impact of forecasting, lead times, and information. Management Science, 46 (3), 436-443.

Chen, L., Lee, H.L. 2009. Information sharing and order variability control under a generalized demand model. Management Science, 55 (5), 781-798.

Choudhary, D., Shankar, R. 2015. The value of VMI beyond information sharing in a single supplier multiple retailers supply chain under a non-stationary $(\mathrm{Rn}, \mathrm{Sn})$ policy. Omega, 51, 59-70.

Christopher, M., \& Holweg, M. 2017. Supply Chain 2.0 revisited: a framework for managing volatilityinduced risk in the supply chain. International Journal of Physical Distribution \& Logistics Management, 47 (2), 2-17.

Costantino, F., Di Gravio, G., Shaban, A., Tronci, M. 2014. The impact of information sharing and inventory control coordination on supply chain performances. Computers and Industrial Engineering, 76, 292-306.

Costantino, F., Di Gravio, G., Shaban, A., Tronci, M. 2015. The impact of information sharing on ordering policies to improve supply chain performances. Computers \& Industrial Engineering, 82, 127-142.

Croson, R., Donohue, K., Katok, E., Sterman, J. 2014. Order stability in supply chains: coordination risk and the role of coordination stock. Production and Operations Management, 23 (2), 176-196.

Datta, P. P., Christopher, M. G. 2011. Information sharing and coordination mechanisms for managing uncertainty in supply chains: a simulation study. International Journal of Production Research, 49(3), $765-803$.

Dejonckheere, J., Disney, S. M., Lambrecht, M. R., Towill, D. R. 2004. The impact of information enrichment on the Bullwhip effect in supply chains: A control engineering perspective. European Journal of Operational Research, 153 (3), 727-750.

Disney, S.M., Lambrecht, M.R. 2008. On replenishment rules, forecasting, and the bullwhip effect in supply chains. Foundations and Trends in Technology, Information and Operations Management, 2 (1), 1-80.

Disney, S.M., Maltz, A., Wang, X., Warburton, R.D.H. 2016. Inventory management for stochastic lead times with order crossovers, European Journal of Operational Research, 248, 473-486. 
Dominguez R., Cannella S., Póvoa A.P., Framinan J.M. 2017. Information sharing in supply chains with heterogeneous retailers. Omega. DOI: https://doi.org/10.1016/j.omega.2017.08.005

Disney, S.M., Towill, D.R. 2003. On the bullwhip and inventory variance produced by an ordering policy. Omega - The International Journal of Management Science, 31 (3), 157-167.

Dominguez, R., Cannella, S., Framinan, J.M. 2014. On bullwhip-limiting strategies in divergent supply chain networks. Computers and Industrial Engineering, 73 (1), 85-95.

Dominguez, R., Cannella, S., Framinan, J.M. 2015a. The impact of the supply chain structure on bullwhip effect. Applied Mathematical Modelling, 39 (23-24), 7309-7325.

Dominguez, R., Cannella, S., Framinan, J.M. 2015b. On returns and network configuration in supply chain dynamics. Transportation Research Part E: Logistics and Transportation Review, 73, 152-167.

Dominguez, R., Framinan, J.M. 2013. A decisión management tool: modelling the order fulfilment process by multi-agent systems. International Journal of Management and Decision Making, 12 (3), 240-258.

Duan, Y., Yao, Y., Huo, J. 2015. Bullwhip effect under substitute products. Journal of Operations Management, 36, 75-89.

Duong, L.N., Wood, L.C., Wang, W.Y. 2015. A multi-criteria inventory management system for perishable \& substitutable products. Procedia Manufacturing, 2, 66-76.

Evers, P. T., \& Wan, X. 2012. Systems analysis using simulation. Journal of Business Logistics, 33(2), 80-89.

Fawcett, S.E., Wallin, C., Allred, C., Fawcett, A.M., Magnan, G.M. 2011. Information technology as an enabler of supply chain collaboration: A dynamic-capabilities perspective. Journal of Supply Chain Management, 47 (1), 38-59.

Ganesh, M., Raghunathan, S., Rajendran, C. 2014a. Distribution and equitable sharing of value from information sharing within serial supply chains. IEEE Transactions on Engineering Management, 61 (2), 6573365, 225-236.

Ganesh, M., Raghunathan, S., Rajendran, C. 2014b. The value of information sharing in a multi-product, multi-level supply chain: Impact of product substitution, demand correlation, and partial information sharing. Decision Support Systems, 58 (1), 79-94.

Geunes, J., Romeijn, H.E., Van Den Heuvel, W. 2016. Improving the efficiency of decentralized supply chains with fixed ordering costs. European Journal of Operational Research, 252 (3), 815-828.

GMA - Grocery Manufacturers Association. 2009. Retail-direct data report. Report, GMA, Washington, DC, http://www.gmaonline .org/downloads/research-and-reports/WP-Retailer-DDR09-6.pdf.

Guertler, B., Spinler, S. 2015. When does operational risk cause supply chain enterprises to tip? A simulation of intra-organizational dynamics. Omega, 57, 54-69.

Hayya, J.C., Bagchi, U., Kim, J.G., Sun, D. 2008. On static stochastic order crossover. International Journal of Production Economics, 114 (1), 404-413. 
Dominguez R., Cannella S., Póvoa A.P., Framinan J.M. 2017. Information sharing in supply chains with heterogeneous retailers. Omega. DOI: https://doi.org/10.1016/j.omega.2017.08.005

Hayya, J.C., Bagchi, U., Ramasesh, R. 2011. Cost relationships in stochastic inventory systems: A simulation study of the (S, S-1, t=1) model. International Journal of Production Economics, 130 (2), 196-202.

Heckmann, I., Comes, T., Nickel, S. 2015. A critical review on supply chain risk-Definition, measure and modeling. Omega, 52, 119-132.

Hiebeler, D. 1994. The Swarm Simulation System and Individual-Based Modeling. Proceedings of Decision Support 2001: Advanced Technology for Natural Resource Management, Toronto, Canada.

Hilletofth, P., Hilmola, O. P., Wang, Y. 2016. Simulation based decision support systems in the supply chain context. Industrial Management \& Data Systems, 116(2).

Holmstrőm, J., Småros, J., Disney, S. M., \& Towill, D. R. (2016). Collaborative supply chain configurations: the implications for supplier performance in production and inventory control. In Developments in Logistics and Supply Chain Management 27-37. Palgrave Macmillan UK.

Hosoda, T., Naim, M. M., Disney, S. M., \& Potter, A. (2008). Is there a benefit to sharing market sales information? Linking theory and practice. Computers \& industrial engineering, 54(2), 315-326.

Huang, B., Iravani, S.M.R. 2005. Production control policies in supply chains with selective-information sharing. Operations Research, 53 (4), 662-674.

Huang, Y.-S., Li, M.-C., Ho, J.-W. 2016. Determination of the optimal degree of information sharing in a two-echelon supply chain. International Journal of Production Research, 54 (5), 1518-1534.

Huo, B., Zhao, X., Zhou, H. 2014. The effects of competitive environment on supply chain information sharing and performance: an empirical study in China. Production and Operations Management, 23(4), 552-569.

Kelton, W.D., Sadowki, R.P., Sadowki, D.A. 2007. Simulation with Arena, fourth ed. McGraw-Hill, New York.

Kembro, J., Selviaridis, K., Näslund, D. 2014. Theoretical perspectives on information sharing in supply chains: a systematic literature review and conceptual framework. Supply Chain Management: An International Journal, 19, 609-625.

Kembro, J., Selviaridis, K. 2015. Exploring information sharing in the extended supply chain: an interdependence perspective. Supply Chain Management: An International Journal, 20(4), 455-470.

Kim, J.G., Chatfield, D., Harrison, T.P., Hayya, J.C. 2006. Quantifying the bullwhip effect in a supply chain with stochastic lead time. European Journal of Operational Research, 173 (2), 617-636.

Kleijnen, JPC. 2008. Simulation experiments in practice: statistical design and regression analysis. Journal of Simulation, 2 (1), 19-27.

Kong, G., Rajagopalan, S., Zhang, H. 2013. Revenue sharing and information leakage in a supply chain. Management Science, 59 (3), 556-572. 
Dominguez R., Cannella S., Póvoa A.P., Framinan J.M. 2017. Information sharing in supply chains with heterogeneous retailers. Omega. DOI: https://doi.org/10.1016/j.omega.2017.08.005

Lau, J.S.K., Huang, G.Q., Mak, K.L. 2004. Impact of information sharing on inventory replenishment in divergent supply chains. International Journal of Production Research, 42 (5), 919-941.

Li, Q., Disney, S.M., Gaalman, G. 2014. Avoiding the bullwhip effect using Damped Trend forecasting and the Order-Up-To replenishment policy. International Journal of Production Economics, 149, 316.

Li, T., Zhang, H. 2015. Information sharing in a supply chain with a make-to-stock manufacturer. Omega, $50,115-125$.

Li, Y., Zhen, X., Qi, X., Cai, G.G. 2016. Penalty and financial assistance in a supply chain with supply disruption. Omega, 61, 167-181.

Lin, F.-R., Huang, S.-H., Lin, S.-C. 2002. Effects of Information Sharing on Supply Chain Performance in Electronic Commerce. IEEE Transactions on Engineering Management, 49 (3), 258-268.

Long, Q and Zhang, W. (2014). An integrated framework for agent based inventory-productiontransportation modeling and distributed simulation of supply chains. Information Sciences, 277, 567581.

Maghsoudi, A., Pazirandeh, A. 2016. Visibility, resource sharing and performance in supply chain relationships: insights from humanitarian practitioners. Supply Chain Management: An International Journal, 21(1), 125-139.

Merzifonluoglu, Y. 2015. Risk averse supply portfolio selection with supply, demand and spot market volatility. Omega, 57, 40-53.

Minar, N., Burkhart, R., Langton, C., Askenazi, M. 1996. The Swarm simulation system: A toolkit for building multi-agent simulations. Working Paper 96-06-042, Santa Fe Institute, Santa Fe.

Nachtmann, H., Waller, M.A., Rieske, D.W. 2010. The impact of point-of-sale data inaccuracy and inventory record data errors. Journal of Business Logistics, 31 (1), 149-158.

Nair, A., Vidal, J.M. 2011. Supply network topology and robustness against disruptions - An investigation using multi-agent model. International Journal of Production Research, 49 (5), 13911404.

Oliveira, J. B., Lima, R. S., Montevechi, J. A. B. 2016. Perspectives and relationships in Supply Chain Simulation: A systematic literature review. Simulation Modelling Practice and Theory, 62, 166-191.

Osadchiy, N., Gaur, V., Seshadri, S. 2015. Systematic risk in supply chain networks. Management Science, 62(6), 1755-1777.

Ponte, B., Sierra, E., de la Fuente, D., \& Lozano, J. 2017. Exploring the interaction of inventory policies across the supply chain: An agent-based approach. Computers \& Operations Research, 78, 335-348.

Rabinovich, E., Cheon, S. 2011. Expanding horizons and deepening understanding via the use of secondary data sources. Journal of Business Logistics, 32(4), 303-316. 
Dominguez R., Cannella S., Póvoa A.P., Framinan J.M. 2017. Information sharing in supply chains with heterogeneous retailers. Omega. DOI: https://doi.org/10.1016/j.omega.2017.08.005

Rached, M., Bahroun, Z., Campagne, J.-P. 2016. Decentralised decision-making with information sharing vs. centralised decision-making in supply chains. International Journal of Production Research, 1-22. Article in Press.

Rahmandad, H., Sterman, J. 2008. Heterogeneity and network structure in the dynamics of diffusion: Comparing agent-based and differential equation models. Management Science, 54(5), 998-1014.

Ramanathan, U. 2014. Performance of supply chain collaboration-A simulation study. Expert Systems with Applications, 41(1), 210-220.

Ren, Z. J. 2017. Empirical Studies in Information Sharing. In Handbook of Information Exchange in Supply Chain Management (pp. 27-38). Springer International Publishing.

Shang, W., Ha, A.Y., Tong, S. 2016. Information sharing in a supply chain with a common retailer. Management Science, 62 (1), 245-263.

Sharma, S. 2010. Policies concerning decisions related to quality level. International Journal of Production Economics, 125 (1), 146-152.

Shih, H.P., Lai, K.H., Cheng, T.E. 2015. Examining structural, perceptual, and attitudinal influences on the quality of information sharing in collaborative technology use. Information Systems Frontiers, 17 (2), 455-470.

Shnaiderman, M., Ouardighi, F.E. 2014. The impact of partial information sharing in a two-echelon supply chain. Operations Research Letters, 42 (3), 234-237.

Spekman, R., Davis, E.W. 2016. The extended enterprise: a decade later. International Journal of Physical Distribution \& Logistics Management, 46 (1), 43-61.

Srinivasan, M., Novack, R., Thomas, D. 2011. Optimal and approximate policies for inventory systems with order crossover. Journal of Business Logistics, 32 (2), 180-193.

Stadtler, H. 2005. Supply chain management and advanced planning - Basics, overview and challenges. European Journal of Operational Research, 163 (3), 575-588.

Sterman, J. 1989. Modeling managerial behavior: misperceptions of feedback in a dynamic decision making experiment. Management Science, 35 (3), 321-339.

Supply Chain Council. 2006. Supply-Chain Operations Reference-model-Overview of SCOR Version 8.0, Washington. Available from: 〈http://www.supply-chain.org>.

Swaminathan, J. M., Smith, S. F., Sadeh, N. M. 1998. Modeling supply chain dynamics: A multiagent approach. Decision sciences, 29(3), 607-632.

Thomas, A., Krishnamoorthy, M., Venkateswaran, J., Singh, G. 2016. Decentralised decision-making in a multi-party supply chain. International Journal of Production Research, 54 (2), 405-425.

Trapero, J.R., Kourentzes, N., Fildes, R. 2012. Impact of information exchange on supplier forecasting performance. Omega, 40 (6), 738-747. 
Dominguez R., Cannella S., Póvoa A.P., Framinan J.M. 2017. Information sharing in supply chains with heterogeneous retailers. Omega. DOI: https://doi.org/10.1016/j.omega.2017.08.005

Trapero, J.R., Pedregal, D.J. 2016. A novel time-varying bullwhip effect metric: An application to promotional sales. International Journal of Production Economics, 182, 465-471.

Wang, X., Disney, S. M. 2016. The bullwhip effect: Progress, trends and directions. European Journal of Operational Research, 250 (3), 691-701.

Wang, X., Disney, S.M. 2017. Mitigating variance amplification under stochastic lead-time: The proportional control approach. European Journal of Operational Research, 256, 151-162.

Xu, K., Dong, Y., Xia, Y. 2015. 'Too little' or 'Too late': The timing of supply chain demand collaboration. European Journal of Operational Research, 241 (2), 370-380.

Yang, T., Wen, Y.-F., Wang, F.-F. 2011. Evaluation of robustness of supply chain information-sharing strategies using a hybrid Taguchi and multiple criteria decision-making method. International Journal of Production Economics, 134 (2), 458-466.

Zissis, D., Ioannou, G., Burnetas, A. 2015. Supply chain coordination under discrete information asymmetries and quantity discounts. Omega, 53, 21-29. 